\title{
The Role of Diet Quality in Mediating the Association between Ultra-Processed Food Intake, Obesity and Health-Related Outcomes: A Review of Prospective Cohort Studies
}

\author{
Samuel J. Dicken ${ }^{1}$ (D) and Rachel L. Batterham ${ }^{1,2,3, * \mathbb{D}}$ \\ 1 Centre for Obesity Research, Department of Medicine, University College London (UCL), \\ London WC1E 6JF, UK; samuel.dicken.20@ucl.ac.uk \\ 2 Bariatric Centre for Weight Management and Metabolic Surgery, University College London \\ Hospital (UCLH), London NW1 2BU, UK \\ 3 National Institute for Health Research, Biomedical Research Centre, University College London \\ Hospital (UCLH), London W1T 7DN, UK \\ * Correspondence: r.batterham@ucl.ac.uk
}

check for

updates

Citation: Dicken, S.J.; Batterham, R.L. The Role of Diet Quality in Mediating the Association between UltraProcessed Food Intake, Obesity and Health-Related Outcomes: A Review of Prospective Cohort Studies. Nutrients 2022, 14, 23. https:// doi.org/10.3390/nu14010023

Academic Editor:

Javier Gómez-Ambrosi

Received: 30 November 2021

Accepted: 16 December 2021

Published: 22 December 2021

Publisher's Note: MDPI stays neutral with regard to jurisdictional claims in published maps and institutional affiliations.

Copyright: (C) 2021 by the authors. Licensee MDPI, Basel, Switzerland. This article is an open access article distributed under the terms and conditions of the Creative Commons Attribution (CC BY) license (https:// creativecommons.org/licenses/by/ $4.0 /)$.

\begin{abstract}
Prospective cohort studies show that higher intakes of ultra-processed food (UPF) increase the risk of obesity and obesity-related outcomes, including cardiovascular disease, cancer and type 2 diabetes. Whether ultra-processing itself is detrimental, or whether UPFs just have a lower nutritional quality, is debated. Higher UPF intakes are inversely associated with fruit, vegetables, legumes and seafood consumption. Therefore, the association between UPFs and poor health could simply be from excess nutrient intake or from a less healthful dietary pattern. If so, adjustment for dietary quality or pattern should explain or greatly reduce the size of the significant associations between UPFs and health-related outcomes. Here, we provide an overview of the literature and by using a novel approach, review the relative impact of adjusting for diet quality/patterns on the reported associations between UPF intake and health-related outcomes in prospective cohort studies. We find that the majority of the associations between UPFs, obesity and health-related outcomes remain significant and unchanged in magnitude after adjustment for diet quality or pattern. Our findings suggest that the adverse consequences of UPFs are independent of dietary quality or pattern, questioning the utility of reformulation to mitigate against the obesity pandemic and wider negative health outcomes of UPFs.
\end{abstract}

Keywords: obesity; diet; ultra-processed food; NOVA classification; diet quality; dietary pattern; non-communicable disease

\section{Introduction}

Obesity (defined as an excess accumulation of fat that may result in adverse health [1]) is a leading cause of poor health, increasing the risk of non-communicable disease (NCD), all-cause mortality and negatively impacting on quality of life [2-4]. Management strategies for obesity prevention and treatment are therefore important.

Diet has long been a cornerstone of weight management, with dietary policies being a core feature of government and health organisation strategies to reduce obesity worldwide. Indeed, poor diets are a leading cause of preventable obesity-related death and NCD, including cancer, cardiovascular disease (CVD) and type 2 diabetes (T2DM), accounting for 11 million deaths annually $[5,6]$. As such, dietary improvements could prevent one in every five deaths [5]. There is converging evidence that a healthy diet consists predominantly of whole, plant-based foods, including fruit, vegetables, pulses, nuts, whole grains and oily fish [7-14]. Such diets, as exemplified by the Mediterranean diet and Dietary Approaches to Stop Hypertension (DASH), are high in fibre and limit saturated fat, sodium and added sugar intake. In contrast, Western diets high in refined grains, red and processed meat, 
sweets and sugar-sweetened beverages are rich in saturated fat, sodium and added sugar and associated with an increased risk of disease [13-17].

Despite the importance of specific nutrients and food groups within overall dietary patterns for health, it is becoming increasingly clear that other dimensions of diets are important [18]. In recent decades, a nutrition transition has resulted in a global shift away from consuming minimally processed foods, and towards ultra-processed alternatives $[19,20]$, away from home-prepared dishes, and towards ready-to-eat meals and snacks [21]. This same period has seen a rapid rise in the global prevalence of obesity in children and adults [22]. Besides their nutrient content, healthy dietary patterns such as the Mediterranean diet tend to be minimally processed [15], and unhealthy dietary patterns such as the Western diet tend to be ultra-processed $[11,16,23]$.

Whether ultra-processed diets are detrimental to health simply because they are of a poor nutritional quality, or whether the nature and extent of processing itself has health consequences is an ongoing debate [24]. Several recent systematic reviews, meta-analyses and reviews have discussed the prevalence of UPF consumption and its impact on healthrelated outcomes. However, no reviews to date have considered how dietary adjustment in prospective cohort studies may alter the significance and magnitude of effect estimates. This review provides a brief overview of the current state of the literature as well as the current key discussion points regarding mechanisms of action, before reviewing in detail the prospective analyses adjusting for dietary quality, which provides important insights into the relative role of nutrient content compared with ultra-processing on obesity risk and adverse health-related outcomes.

\section{NOVA Classification}

Several classification systems have been developed to categorise food and drink based on levels of processing, including the International Food Information Council, International Agency for Research on Cancer and NOVA classifications [25]. The most commonly used is the NOVA classification, which considers the nature, extent and purpose of processing, not the act of processing itself, to be important [26]. The NOVA food classification consists of four groups: minimally processed foods (MPF), processed culinary ingredients (PCI), processed foods (PF) and ultra-processed foods (UPF) (Table 1) [27]. UPFs are industrial formulations, typically with five or more ingredients including additives, flavourings and colours that no longer resemble their original constituent ingredients [28]. Nutritional quality, such as nutrients to limit content, is not a core aspect of the NOVA classification.

In recent decades, the contribution of UPFs to diets worldwide has been increasing year on year [29]. In the US and UK, over 55\% of the average daily energy intake now comes from UPFs, and those in the highest quintiles consume over $75 \%$ of their daily energy intake from UPFs [30]. Additionally, UPFs are becoming increasingly more prevalent in the diets of infants, children and adolescents [31,32]. 
Table 1. Definition of NOVA classifications, from Monteiro et al., 2019 [28].

\begin{tabular}{|c|c|c|}
\hline Group & Definition & Examples \\
\hline $\begin{array}{l}\text { 1. Unprocessed and } \\
\text { minimally processed foods }\end{array}$ & $\begin{array}{l}\text { Unprocessed foods altered by processes such } \\
\text { as the removal of inedible or unwanted parts, } \\
\text { drying, crushing, grinding, fractioning, } \\
\text { roasting, boiling, pasteurisation, refrigeration, } \\
\text { freezing, placement in containers, vacuum } \\
\text { packaging or non-alcoholic fermentation. Salt, } \\
\text { sugar, oils or fats, or other food substances are } \\
\text { not added. The primary aim is to extend the } \\
\text { life of the food, enabling storage for longer use, } \\
\text { and to make preparation easier or } \\
\text { more diverse. }\end{array}$ & $\begin{array}{l}\text { Fresh, squeezed, chilled, frozen, or dried fruit, } \\
\text { leafy and root vegetables, brown rice, white } \\
\text { rice, corn cob, beans, lentils, chickpeas, } \\
\text { potatoes, sweet potatoes, mushrooms, meat, } \\
\text { poultry, fish, seafood, meat cuts, eggs, fresh or } \\
\text { pasteurised milk or plain yoghurt, fresh or } \\
\text { pasteurised fruit or vegetable juices (with no } \\
\text { added sugar, sweeteners or flavours), grits, } \\
\text { flakes or flour made from corn, wheat, oats, or } \\
\text { cassava, nuts and other oily seeds (with no } \\
\text { added salt or sugar), herbs and spices used in } \\
\text { culinary preparations, such as thyme, oregano } \\
\text { and pepper, tea, coffee, and water. }\end{array}$ \\
\hline
\end{tabular}

Substances derived from unprocessed and minimally processed foods, or from nature.

2. Processed culinary ingredients
They are created by industrial processes including pressing, centrifuging, refining, extracting or mining, and used in the preparation, seasoning and cooking of group 1 foods.
Industrial products made by adding processed culinary ingredients found in group 2 to group 1 foods, using preservation methods such as canning and bottling. For breads and cheeses, non-alcoholic fermentation is used. Food processing in group 3 aims to increase the durability of group 1 foods and make them more enjoyable, by modifying or enhancing their sensory qualities.
Oils and fats, sugar and salt.
3. Processed foods
Formulations of ingredients, mostly of exclusive industrial use, resulting from a series of industrial processes, many requiring sophisticated equipment and technology.

Processes enabling the manufacture of ultra-processed foods include the fractioning of whole foods into substances, chemical

4. Ultra-processed foods modifications of these substances, assembly of unmodified and modified food substances using industrial techniques such as extrusion, moulding and pre-frying, frequent application of additives whose function is to make the final product palatable or hyper-palatable ('cosmetic additives'), and sophisticated packaging, usually with synthetic materials.
Canned or bottled vegetables and legumes in brine, salted or sugared nuts and seeds, salted, dried, cured, or smoked meats and fish, canned

fish (with or without added preservatives), fruits in syrup (with or without added antioxidants), freshly made unpackaged breads and cheeses.
Carbonated soft drinks, sweet or savoury packaged snacks, chocolate, confectionery, ice cream, mass-produced packaged breads and

buns, margarines, biscuits, pastries, cakes, breakfast 'cereals', pre-prepared pies and pasta and pizza dishes, poultry or fish nuggets,

sausages, burgers, hot dogs and other reconstituted meat products, powdered and packaged 'instant' soups, noodles and desserts.

\section{UPFs, Obesity Risk and Health-Related Outcomes}

Systematic reviews and meta-analyses of prospective cohort studies and cross-sectional studies show that UPF consumption is associated with an increased risk of weight gain, overweight and obesity [33-38], as well as other obesity-related health outcomes [33,34], including hypertension, type 2 diabetes (T2DM) [38,39], cancer [33], cardiovascular disease (CVD) [33,34], depression and all-cause mortality [33,35-37,40]. In Europe, a 1\% increase in the national household availability of UPFs is associated with a $0.25 \%$ increase in the national prevalence of obesity, after adjusting for income, physical inactivity and smoking [41]. Additionally, increases in ultra-processed food and drink volume sales per 
capita are associated with population-level BMI trajectories [42]. The rising contribution of UPFs to diets worldwide poses a significant threat to addressing the obesity epidemic.

\section{Mechanisms and Current Debates around Ultra-Processing: Correlation or Causation?}

There is increasing evidence showing that UPFs are linked with obesity and other adverse health-related outcomes. However, the potential mechanisms that lead to these adverse health outcomes are diverse, and still largely debated (readers are directed to other comprehensive overviews for further reading on potential mechanisms [43-45]). These mechanisms can be broadly considered as being as a result of nutrient content, or as a result of ultra-processing [43].

From a nutrient perspective, UPFs have on average a higher energy density ( $2.3 \mathrm{vs.}$ $1.1 \mathrm{kcal} / \mathrm{g}$ ) and lower nutrient density than minimally processed foods [44,46]. UPFs tend to be high in saturated fat, added sugar and sodium [47], with meta-analyses demonstrating that diets higher in UPFs tend to contain greater intakes of total energy, free sugars and total and saturated fat, and lower intakes of fibre, protein and some micronutrients [30,48]. The high palatability of UPFs has the potential to promote a faster eating rate and energy overconsumption [44], with daily energy intake increasing as the proportion of daily energy intake from UPFs increases ( $3.47 \mathrm{kcal}$ increase per 1\% increase in daily energy intake from UPFs) [30].

However, aspects of ultra-processing may also increase the risk of obesity and other adverse health-related outcomes. Textural and structural changes to the food matrix as a result of ultra-processing can also allow for UPFs to be consumed more quickly [49-51]. Reducing the oro-sensory exposure (OSE) time of a food can delay the onset of satiation [52], and UPFs have been shown to be less satiating than minimally processed foods [53,54]. The delayed satiation from faster eating rates can promote increased energy intake [55]. Food matrix changes can also alter nutrient bioavailability, and the harm from UPFs may come from the fact that they tend to be more hyperglycaemic than MPFs [53,54]. Besides the nutritional quality of UPFs and degradation of the food matrix, the additive content and excessive heat treatment of UPFs have also been proposed to lead to changes in gut microbiota and promote inflammation [56,57].

Beyond nutrients and ultra-processing, behavioural aspects of UPFs and the local, environmental and systemic drivers influencing food choice are also important [58]. The heavy marketing [59,60], low cost [46], high availability [61] and large portion sizes of UPFs $[43,62]$ can make them preferable choices over minimally processed options.

\section{UPF Removal or UPF Reformulation: The Case for 'Healthy' UPFs?}

Actions to reduce the risks associated with UPF intake have largely been either reformulation to improve the nutrient profile of UPFs, or avoidance of UPFs altogether. Whether experts support UPF reformulation or UPF avoidance is dependent on the views regarding which mechanisms link UPFs with poor health.

Both those in favour of limiting UPFs [63], and those against the NOVA classification [64-66], acknowledge that the nutritional quality of UPFs is an important factor. Even some proponents of NOVA and reducing UPF intake have suggested that the saturated fat, added sugar and sodium content of UPFs is important, despite this not being a core aspect of the UPF definition [28]. For example, authors have focussed on the impact of reducing UPF intake on changes in saturated fat, added sugar and sodium intake and dietary quality, and the subsequent benefit of these changes on disease risk [67-70]. Critics of NOVA/supporters of reformulation argue that any link between UPFs and adverse health is solely due to their nutrient content; that some UPFs are just high in saturated fat, added sugar and sodium and that some UPFs are not nutritionally inferior, with some studies showing no difference in saturated fat, added sugar and sodium intakes across extremes of UPF intake $[64,71,72]$. 
Indeed, many UPFs are nutritionally poor and energy dense, but not all are. Studies demonstrate that UPFs tend to relate with existing nutrient profile indices, based on saturated fat, added sugar and sodium content [73]. In comparison with the Nutri-Score (ranking foods from class A to E, where A is high and $\mathrm{E}$ is low nutritional quality) used across several European countries, the majority of UPFs are class C, D or E, whereas the majority of unprocessed or minimally processed foods are class A or B [74]. However, $26 \%$ of class A foods are UPFs, largely being UPF ready meals or dairy products. Studies comparing UPFs with other nutrient indices (such as the Nutrient Rich Foods index, based on the protein, fibre, vitamins, minerals, saturated fat, added sugar and sodium content of food) show similar findings; most UPFs are low in nutritional quality, but some are high, and most MPFs are high in nutritional quality, but some are still low in quality [46]. Indeed, a range of UPFs have been identified as being 'healthy', based on nutrient profiling [65]. 'Healthy' UPFs are often reformulations and plant-based alternatives [65,74], which carry nutritional claims such as 'fat free', 'reduced salt', 'low sugars or 'added fibre' according to European Food Safety Authority guidelines [75]. Other 'healthy' UPFs such as fortified bread have been suggested to be important sources of vitamins and minerals $[64,65,76]$, and avoidance of such UPFs may result in micronutrient deficiencies [77]. Therefore, two foods can be defined as having a high level of nutritional quality, but with very different levels of processing [78].

Given that particular UPFs, such as reformulations, can be considered to be of a similar or greater nutritional quality than some MPFs, it has been suggested that these UPFs are therefore healthy and nutritious $[65,76]$. Experts proposing that reformulations are sufficient to address all issues surrounding UPFs are making the assumption that the association between UPF intake and adverse health is mediated solely by their content of specific nutrients [71]. Experts proposing avoidance of all UPFs and arguing that reformulations are insufficient to significantly improve health are making the assumption that no UPFs can be considered to be healthy [79]. Such experts argue that reformulation does not address aspects of ultra-processing [80-82]; reformulated UPFs still have a degraded food matrix [83,84], and components of the raw constituent foods are still lost [85].

In summary, there is agreement that energy dense foods high in saturated fat, sodium and added sugar are harmful to health and should be limited. Such foods also tend to be ultra-processed, but not all are $[73,74]$. Despite the mounting evidence showing the adverse impacts of UPFs, the argument between nutrients and ultra-processing, and therefore between reformulation or avoidance of UPFs, is ongoing [24,81,82]. Further research understanding the relative impact of nutrients vs. ultra-processing is therefore warranted. However, largely overlooked to date, is the fact that many published prospective cohort studies have already considered the overlap between nutrition and ultra-processing, performing dietary adjustments of models to delineate the association between UPF intake, obesity and adverse health-related outcomes.

\section{Review of Prospective Studies Adjusting for Dietary Quality}

One of the main criticisms against the NOVA classification is that UPFs simply capture nutrient poor foods high in saturated fat, sodium and added sugar [71,73]. Furthermore, it is well established that the overall dietary pattern is important for health [10]. Higher UPF intakes are inversely associated with MPF intake, including fruit, vegetables, cereals, beans, legumes and seafood intake [30]. Therefore, the association between high UPF intake and poor health could simply be from excess nutrient intake, or from a less healthful dietary pattern. If this were the case, adjustment for participants' dietary saturated fat, sugar and sodium intake, or adjustment for their overall dietary pattern should explain the significant associations found between higher intakes of UPF and adverse health-related outcomes in prospective cohort studies, either rendering the association to be non-significant, or greatly reducing the size of the association.

Many prospective studies in adults have performed dietary adjustments, with only a small proportion not adjusting for aspects of dietary quality [86-91]. A greater proportion 
of prospective studies during gestation [92,93], or in children [94-101], have not performed dietary adjustments. These dietary adjustments can be broadly classed as adjustment for fat (typically saturated fat), carbohydrate (typically sugar) and sodium, adjustment for dietary patterns (including Mediterranean diet, Healthy Eating Index (HEI), Alternate Healthy Eating Index (AHEI), Dietary Guidelines for Americans Adherence Index (DGAI), healthy and Western dietary patterns and Food Standards Agency Nutrient Profiling System Dietary Index (FSA-NPS-DI)), or other dietary adjustments (typically for specific food groups such as fruit and vegetables).

Table 2 presents the 37 longitudinal, observational studies that report some form of adjustment for diet quality/pattern in their analyses investigating the association between UPF intake as defined by NOVA, and health-related outcomes (the search process and criteria for the review is detailed in the Supplementary Materials). Table 2 also presents the association between UPF intake and health-related outcomes from adjusted models preceding the dietary adjustment, or where not reported, the adjusted model including the dietary adjustment.

Across 37 studies, 87 health-related outcomes were assessed using 91 models. Of the 66 models that demonstrate a significant association between UPF and a health-related outcome, 64 remained significant following adjustment for diet quality or diet pattern. In total, 136/142 dietary adjustments did not explain the significance of the association between UPF intake and a health-related outcome. Across four studies, all four models demonstrated higher UPF intakes were significantly associated with all-cause mortality [102-105]. No dietary adjustments (15/15) altered the significance of UPF intake with all-cause mortality. Across 13 models within five studies, 11 were significantly associated with a CVD outcome [104,105,117-119]. 29/31 dietary adjustments did not alter the significance of UPF intake with CVD outcomes. Across two studies, UPF intake was significantly associated with cancer outcomes in $2 / 5$ models $[105,126] .8 / 8$ dietary adjustments did not alter the significance of the association between UPF intake and the two cancer outcomes. In two models significantly associated with T2DM, 7/7 dietary adjustments did not alter the significance [123,124]. Across nine studies, 23/26 models demonstrated a significant association between UPF intake and adult and child anthropometrics (weight/body mass index (BMI)/fat mass index (FMI) gain, other measures of adiposity and risk of overweight/obesity) [106-113,115]. 40/43 dietary adjustments did not alter the significance of these associations.

\subsection{Adjustment for Saturated Fat, Sugar and Sodium, and for Dietary Pattern}

Table 3 presents the adjustments for saturated fat, sodium and added sugar. Table 4 presents the adjustments for dietary pattern. All but one study retained the significant association between UPF and the health-related outcome after adjustments for saturated fat, sodium and added sugar intake. All but two studies retained the significant association between UPF and the health-related outcome after adjustment for dietary pattern. 
Table 2. Characteristics of prospective studies assessing the association between UPF intake and health-related outcomes whilst also reporting dietary adjustments.

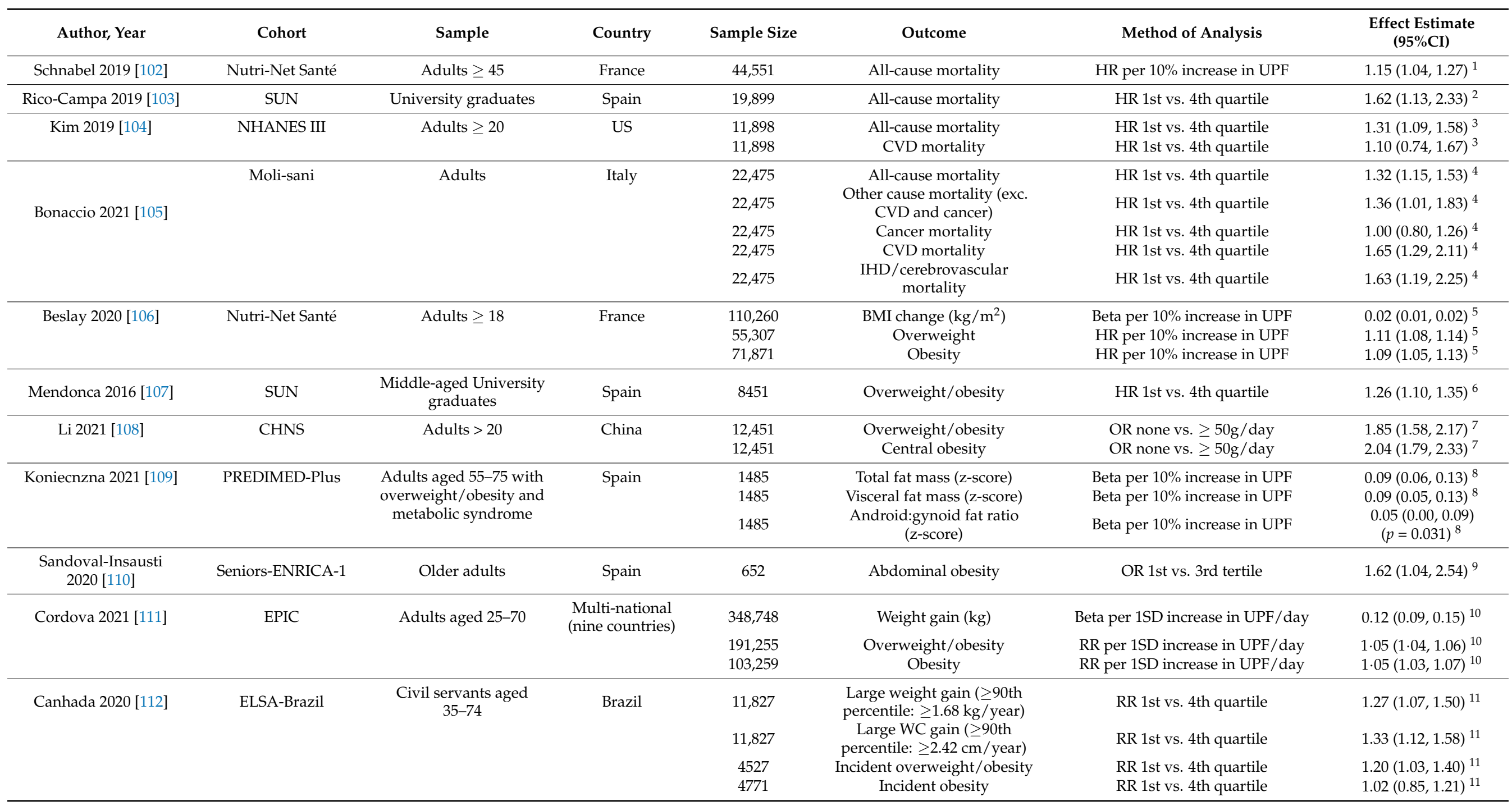


Table 2. Cont.

\begin{tabular}{|c|c|c|c|c|c|c|c|}
\hline Author, Year & Cohort & Sample & Country & Sample Size & Outcome & Method of Analysis & $\begin{array}{l}\text { Effect Estimate } \\
\quad(95 \% \mathrm{CI})\end{array}$ \\
\hline \multirow[t]{4}{*}{ Rohatgi 2017 [113] } & \multirow{4}{*}{$\begin{array}{l}\text { Women's Health } \\
\text { Center and Obstetrics } \\
\text { \& Gynecology Clinic }\end{array}$} & & \multirow[t]{4}{*}{ MO, US } & 45 & \multirow{4}{*}{$\begin{array}{l}\text { Gestational weight gain }(\mathrm{kg}) \\
\text { Neonate thigh skinfold } \\
\text { thickness }(\mathrm{mm}) \\
\text { Neonate subscapular skinfold } \\
\text { thickness }(\mathrm{mm}) \\
\text { Neonate body fat } \\
\text { percentage }(\%)\end{array}$} & Beta per $1 \%$ increase in UPF intake & $1.3(0.3,2.4)^{12}$ \\
\hline & & & & 45 & & Beta per $1 \%$ increase in UPF intake & $0.20(0.005,0.40)^{12}$ \\
\hline & & & & 45 & & Beta per $1 \%$ increase in UPF intake & $0.10(0.02,0.30)^{12}$ \\
\hline & & & & 45 & & Beta per $1 \%$ increase in UPF intake & $0.60(0.04,1.20)^{12}$ \\
\hline \multirow[t]{2}{*}{ Leone 2021 [114] } & \multirow[t]{2}{*}{ SUN } & Females & \multirow[t]{2}{*}{ Spain } & 3730 & Gestational diabetes & OR 1st vs. 3rd tertile & $1.10(0.74,1.64)^{13}$ \\
\hline & & Females $\geq 30$ & & 1192 & Gestational diabetes & OR 1st vs. 3rd tertile & $2.05(1.03,4.07)^{13}$ \\
\hline \multirow[t]{4}{*}{ Chang 2021 [115] } & \multirow[t]{4}{*}{ ALSPAC } & \multirow[t]{4}{*}{ Children } & \multirow[t]{4}{*}{ Britain } & 9020 & \multirow{4}{*}{$\begin{array}{c}\text { BMI }\left(\mathrm{kg} / \mathrm{m}^{2}\right) / \text { year } \\
\text { Fat mass index }\left(\mathrm{kg} / \mathrm{m}^{2}\right) / \text { year } \\
\text { Lean mass index } \\
\left(\mathrm{kg} / \mathrm{m}^{2}\right) / \text { year } \\
\text { Body fat percentage }(\%) / \text { year }\end{array}$} & Beta 1st vs. 5th quintile & $0.06(0.04,0.08)^{14}$ \\
\hline & & & & 8078 & & Beta 1st vs. 5th quintile & $0.03(0.01,0.05)^{14}$ \\
\hline & & & & 8078 & & Beta 1st vs. 5th quintile & $0.004(-0.007,0.01)^{14}$ \\
\hline & & & & 8078 & & Beta 1st vs. 5th quintile & $0.004(-0.05,0.06)^{14}$ \\
\hline Costa $2021[116]$ & $\begin{array}{l}\text { Pelotas-Brazil } 2004 \\
\text { Birth Cohort }\end{array}$ & 6-11-year-olds & Brazil & 4231 & Fat mass index $\left(\mathrm{kg} / \mathrm{m}^{2}\right)$ & Beta $/ 100 \mathrm{~g}$ increase in UPF intake & $0.09(0.07,0.10)^{15}$ \\
\hline \multirow[t]{2}{*}{ Srour 2019 [117] } & \multirow{2}{*}{ Nutri-Net Santé } & \multirow[t]{2}{*}{ Adults $\geq 18$} & \multirow[t]{2}{*}{ France } & 105,159 & All CVD & HR per $10 \%$ increase in UPF & $1.12(1.05,1.20)^{16}$ \\
\hline & & & & 105,159 & Cerebrovascular disease & HR per $10 \%$ increase in UPF & $1.11(1.01,1.21)^{16}$ \\
\hline \multirow[t]{4}{*}{ Juul 2021 [118] } & \multirow[t]{4}{*}{$\begin{array}{c}\text { Framingham } \\
\text { Offspring Cohort }\end{array}$} & \multirow[t]{4}{*}{ Adults } & \multirow[t]{4}{*}{ US } & 3003 & Overall CVD & HR per serving UPF/day & $1.05(1.02,1.08)^{17}$ \\
\hline & & & & 3003 & CVD mortality & HR per serving UPF/day & $1.09(1.02,1.16)^{17}$ \\
\hline & & & & 3003 & Incident hard CVD & HR per serving UPF/day & $1.07(1.03,1.12)^{17}$ \\
\hline & & & & 3003 & Hard coronary heart disease & HR per serving UPF/day & $1.09(1.04,1.15)^{17}$ \\
\hline \multirow[t]{3}{*}{ Zhong 2021 [119] } & \multirow{3}{*}{$\begin{array}{l}\text { Prostate, Lung, } \\
\text { Colorectal, and } \\
\text { Ovarian Cancer } \\
\text { Screening Trial }\end{array}$} & \multirow{3}{*}{$\begin{array}{l}\text { Adults aged } 55-74 \text { at } \\
\text { baseline }\end{array}$} & \multirow[t]{3}{*}{ US } & 91,891 & CVD mortality & HR 1st vs. 5th quintile & $1.50(1.36,1.64)^{18}$ \\
\hline & & & & 91,891 & Heart disease mortality & HR 1st vs. 5th quintile & $1.68(1.50,1.87)^{18}$ \\
\hline & & & & 91,891 & $\begin{array}{c}\text { Cerebrovascular disease } \\
\text { mortality }\end{array}$ & HR 1st vs. 5th quintile & $0.94(0.76,1.17)^{18}$ \\
\hline \multirow[t]{3}{*}{ Scaranni 2021 [120] } & \multirow{3}{*}{ ELSA-Brasil } & \multirow[t]{3}{*}{$\begin{array}{l}\text { Civil servants aged } \\
35-74 \text { at baseline }\end{array}$} & \multirow[t]{3}{*}{ Brazil } & 8754 & Incident hypertension & OR 1st vs. 3rd tertile & $1.20(1.04,1.40)^{19}$ \\
\hline & & & & 8754 & Change in SBP & Beta 1st vs. 3rd tertile & $-0.37(-1.05,0.30)^{19}$ \\
\hline & & & & 8754 & Change in DBP & Beta 1st vs. 3rd tertile & $0.19(-0.28,0.66)^{19}$ \\
\hline
\end{tabular}


Table 2. Cont.

\begin{tabular}{|c|c|c|c|c|c|c|c|}
\hline Author, Year & Cohort & Sample & Country & Sample Size & Outcome & Method of Analysis & $\begin{array}{c}\text { Effect Estimate } \\
(95 \% \mathrm{CI})\end{array}$ \\
\hline \multirow[t]{3}{*}{ Monge 2021 [121] } & \multirow{3}{*}{$\begin{array}{l}\text { Mexican Teachers' } \\
\text { Cohort }\end{array}$} & \multirow{3}{*}{$\begin{array}{c}\text { Females aged } \geq 25 \text { at } \\
\text { baseline }\end{array}$} & \multirow[t]{3}{*}{ Mexico } & 64,934 & Incident hypertension & \multirow{3}{*}{$\begin{aligned} & \leq 20 \% \text { vs. }> 45 \% \text { of energy from } \\
& \text { any UPF } \\
& \leq 20 \% \text { vs. }>45 \% \text { of energy from } \\
& \text { liquid UPF } \\
& \leq 20 \% \text { vs. }>45 \% \text { of energy from } \\
& \text { solid UPF }\end{aligned}$} & $0.99(0.85,1.15)^{20}$ \\
\hline & & & & 64,934 & Incident hypertension & & $1.33(1.09,1.63)^{20}$ \\
\hline & & & & 64,934 & Incident hypertension & & $0.91(0.82,1.01)^{20}$ \\
\hline Mendonca 2017 [122] & SUN & $\begin{array}{l}\text { Middle-aged University } \\
\text { graduates }\end{array}$ & Spain & 14,790 & Hypertension & HR 1st vs. 3rd tertile & $1.23(1.09,1.38)^{21}$ \\
\hline $\begin{array}{c}\text { Llavero-Valero } 2021 \\
\text { [123] }\end{array}$ & SUN & $\begin{array}{l}\text { Middle-aged University } \\
\text { graduates }\end{array}$ & Spain & 20,060 & $\mathrm{~T} 2 \mathrm{DM}$ & HR 1st vs. 3rd tertile & $1.53(1.06,2.22)^{22}$ \\
\hline Srour 2020 [124] & Nutri-Net Santé & Adults $\geq 18$ & France & 104,707 & $\mathrm{~T} 2 \mathrm{DM}$ & HR per $10 \%$ increase in UPF & $1.15(1.06,1.25)^{23}$ \\
\hline Zhang 2021 [125] & TCLSIH & Adults aged $18-90$ & China & 16,168 & NAFLD & HR 1st vs. 4th quartile & $1.17(1.07,1.29)^{24}$ \\
\hline \multirow[t]{4}{*}{ Fiolet 2018 [126] } & \multirow[t]{4}{*}{ Nutri-Net Santé } & \multirow[t]{4}{*}{ Adults $\geq 18$} & \multirow[t]{4}{*}{ France } & 104,980 & All cancers & HR per $10 \%$ increase in UPF & $1.12(1.06,1.18)^{25}$ \\
\hline & & & & 104,980 & Breast cancer & HR per $10 \%$ increase in UPF & $1.11(1.02,1.22)^{25}$ \\
\hline & & & & 104,980 & Prostate cancer & HR per $10 \%$ increase in UPF & $0.98(0.83,1.16)^{25}$ \\
\hline & & & & 104,980 & Colorectal cancer & HR per $10 \%$ increase in UPF & $1.13(0.92,1.38)^{25}$ \\
\hline Vasseur 2021 [127] & Nutri-Net Santé & Adults $\geq 18$ & France & 105,832 & IBD & RR 1st vs. 3rd tertile & $1.32(0.75,2.34)^{26}$ \\
\hline \multirow{2}{*}{ Narula 2021 [128] } & \multirow{2}{*}{ PURE } & \multirow{2}{*}{ Adults aged $35-70$} & \multirow{2}{*}{$\begin{array}{l}21 \text { low, middle, } \\
\text { and high } \\
\text { income } \\
\text { countries }\end{array}$} & 116,087 & Crohn's disease & HR $<1$ vs. $\geq 5$ servings UPF/day & $4.50(1.67,12.13)^{27}$ \\
\hline & & & & 116,087 & Ulcerative Colitis & HR $<1$ vs. $\geq 5$ servings UPF/day & $1.46(0.93,2.28)^{27}$ \\
\hline \multirow[t]{4}{*}{ Schnabel 2018 [129] } & \multirow[t]{4}{*}{ Nutri-Net Santé } & \multirow[t]{4}{*}{ Adults } & \multirow[t]{4}{*}{ France } & 33,343 & Irritable bowel syndrome & OR 1st vs. 4th quartile & $1.24(1.12,1.38)^{28}$ \\
\hline & & & & 33,343 & Functional Constipation & OR 1st vs. 4th quartile & $1.00(0.87,1.15)^{28}$ \\
\hline & & & & 33,343 & Functional diarrhoea & OR 1st vs. 4th quartile & $0.94(0.71,1.26)^{28}$ \\
\hline & & & & 33,343 & Functional dyspepsia & OR 1st vs. 4th quartile & $1.26(1.07,1.48)^{28}$ \\
\hline \multirow[t]{2}{*}{ Lo 2021 [130] } & \multirow[t]{2}{*}{ NHS, NHS II, HPFS } & \multirow[t]{2}{*}{$\begin{array}{l}\text { Adult health } \\
\text { professionals }\end{array}$} & \multirow[t]{2}{*}{ US } & 245,112 & Crohn's disease & HR 1st vs. 4th quartile & $1.75(1.29,2.35)^{29}$ \\
\hline & & & & 245,112 & Ulcerative Colitis & HR 1st vs. 4th quartile & $1.25(0.97,1.62)^{29}$ \\
\hline Adjibade 2019 [131] & Nutri-Net Santé & Adults aged $18-86$ & France & 26,730 & Depressive symptoms & HR per $10 \%$ increase in UPF & $1.21(1.15,1.27)^{30}$ \\
\hline $\begin{array}{c}\text { Gómez-Donoso } 2020 \\
\text { [132] }\end{array}$ & SUN & $\begin{array}{l}\text { Middle-aged University } \\
\text { graduates }\end{array}$ & Spain & 14,907 & Incident depression & HR 1st vs. 4th quartile & $1.41(1.15,1.73)^{31}$ \\
\hline Rey-Garcia 2021 [133] & Seniors-ENRICA-1 & Adult $\geq 60$ & Spain & 1312 & Renal function & OR 1st vs. 3rd tertile & $1.75(1.16,2.64)^{32}$ \\
\hline Zhang 2021 [134] & TCLSIH & Adults $\geq 18$ & China & 18,444 & Hyperuricemia & HR 1st vs. 4th quartile & $1.21(1.10,1.33)^{33}$ \\
\hline
\end{tabular}


Table 2. Cont.

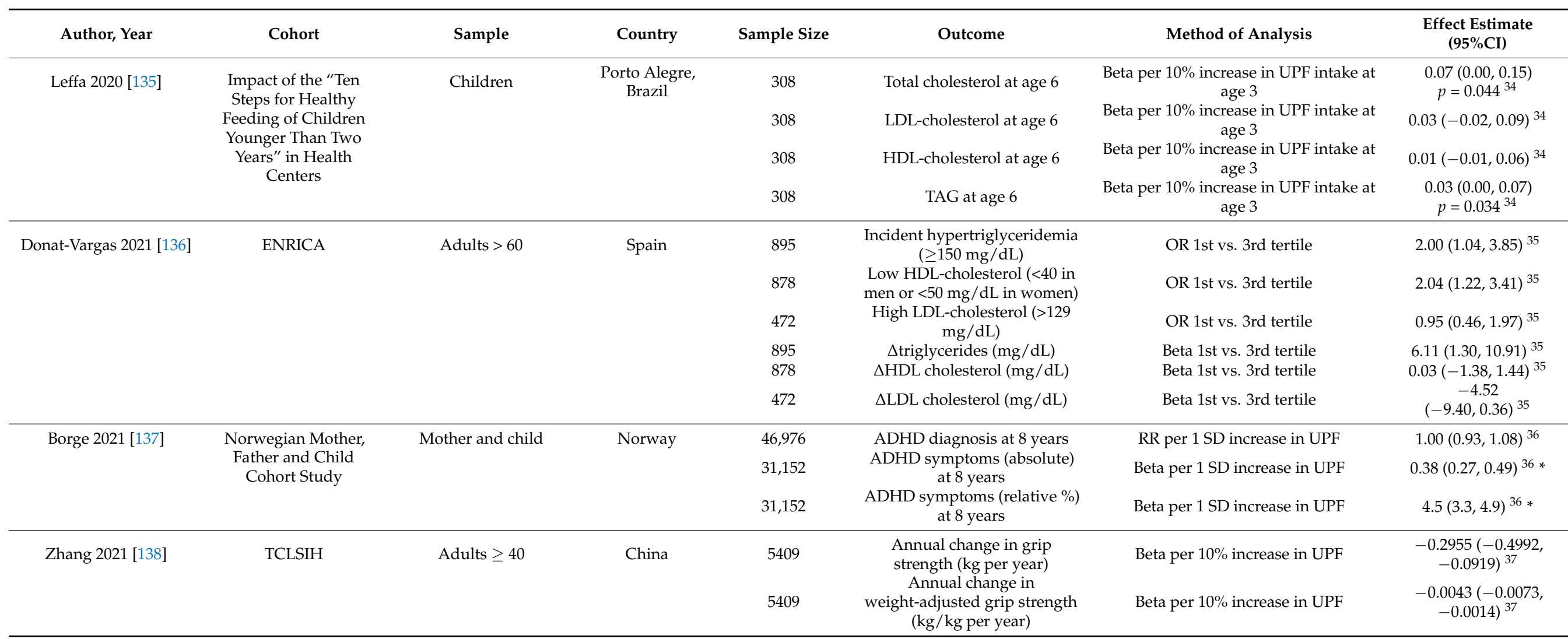

Effect estimates are presented from adjusted models preceding the dietary adjustment, or where not performed, the adjusted model including dietary adjustment. OR, odds ratio; $\mathrm{HR}$, hazard ratio; RR, relative risk; SD, standard deviation; ADHD, attention deficit hyperactivity disorder; CVD, cardiovascular disease; IHD, ischaemic heart disease; BMI, body mass index; T2DM, type 2 diabetes mellitus; UPF, ultra-processed food; SBP, systolic blood pressure; DBP, diastolic blood pressure; LDL, low-density lipoprotein; HDL, high-density lipoprotein; TAG, triacylglycerol; SUN, Seguimiento University of Navarra; NHANES III, Third National Health and Nutrition Examination Survey; CHNS, China Health and Nutrition Survey; Seniors-ENRICA 1, Seniors Study on Nutrition and Cardiovascular Risk in Spain; EPIC, European Prospective Investigation into Cancer and Nutrition; ELSA-Brazil, Brazilian Longitudinal Study of Adult Health; ALSPAC, Avon Longitudinal Study of Parents and Children; TCLSIH, Tianjin Chronic Low-grade Systemic Inflammation and Health; PURE, Prospective Urban Rural Epidemiology; NHS, Nurses' Health Study 1986-2014); NHS II, Nurses' Health Study II (1991-2017); HPFS, Health Professionals Follow-up Study; ${ }^{1}$ Adjusted 
for sex, age, income level, education level, marital status, residence, BMI, physical activity level, smoking status, energy intake, alcohol intake, season of food records, first-degree family history of cancer or cardiovascular diseases and number of food records. ${ }^{2}$ Adjusted for age, sex, marital status, physical activity, smoking status, snacking, special diet at baseline, BMI, total energy intake, alcohol consumption, family history of CVD, diabetes or hypertension at baseline, self-reported hypercholesterolaemia, baseline CVD, cancer or depression, education level and lifelong smoking stratified by recruitment period, deciles of age, sedentary index (sum of hours each day spent watching television, using a computer and driving) and television viewing. ${ }^{3}$ Adjusted for age, sex, race/ethnicity, total energy intake, poverty level, education level, smoking status, physical activity and alcohol intake. ${ }^{4}$ Adjusted for sex age, energy intake, educational level, housing tenure, smoking, BMI, leisure-time physical activity, history of cancer, CVD, diabetes, hypertension and hyperlipidaemia and residence ${ }^{5}$ Adjusted for age, sex, marital status, educational level, physical activity, smoking status, alcohol consumption, energy intake and number of dietary records (overweight and obesity outcomes further adjusted for baseline BMI). ${ }^{6}$ Adjusted for age, sex, marital status, educational status, physical activity, television watching, siesta sleep, smoking status, snacking between meals, following a special diet at baseline and baseline BMI. ${ }^{7}$ Adjusted for age, sex and energy intake. ${ }^{8}$ Adjusted for age, sex, study arm, follow-up time, educational level, marital status, smoking habits, type 2 diabetes prevalence, height and repeated measures of physical activity and sedentary behaviour. ${ }^{9}$ Adjusted for age, sex, educational level, marital status, smoking, ex-drinker status, physical activity in the household and at leisure time, number of medications consumed per day and number of chronic diseases diagnosed by a doctor (chronic obstructive pulmonary disease/asthma, coronary heart disease, stroke, heart failure, osteoarthritis or depression). ${ }^{10}$ Adjusted for age, sex, baseline BMI, educational level, physical activity, ba pline al 作 centre, income, school achievement, smoking and physical activity. Additionally for incident overweight/obesity and weight gain: baseline BMI. Additionally for waist gain: waist circumference at baseline. ${ }^{12}$ Adjusted for maternal age, race, socioeconomic status, weight status, average daily energy intake, time spent in moderate physical activity and fat intake. ${ }^{13}$ Adjusted for age, BMI, education, smoking status, physical activity, family history of diabetes, recruitment year, time between recruitment and the first pregnancy or gestational diabetes, number of pregnancies during follow-up, parity, multiple pregnancies, time spent watching TV, hypertension, following a nutritional therapy and energy intake. ${ }^{14}$ Adjusted for age, baseline UPF, age*baseline UPF interaction term, child sex, race, birth weight, physical activity, quintiles of Index of Multiple Deprivation, the mother's prepreonancy BMI, marital status, highest educational attainment, socioeconomic status and the child's baseline total energy intake. ${ }^{15}$ Adjusted for skin colour, maternal age and schooling, birthweight and sex, screen time and energy intake/expenditure ratio. ${ }^{16}$ Adjusted for age, sex, energy intake, number of 24-h dietary records, smoking status, educational level, physical activity, BMI, alcohol intake and family history of CVD. ${ }^{17}$ Adjusted for age, sex, education, smoking status, alcohol intake and physical activity. ${ }^{18}$ Adjusted for age, sex, race, educational level, marital status, study centre, aspirin use, history of hypertension or diabetes, smoking status, alcohol consumption, BMI, physical activity and energy intake. ${ }^{19}$ Adjusted for age, sex, colour or race, education, time since baseline and SBP/DBP/hypertension. ${ }^{20}$ Adjusted for age, indigenous, internet access, insurance, family history of hypertension, menopausal status, smoking status and physical activity. ${ }^{21}$ Adjusted for age, sex, physical activity, hours of TV watching, baseline BMI, smoking status, use of analgesics, following a special diet at baseline, family history of hypertension, hypercholesterolaemia and alcohol consumption. ${ }^{22}$ Adjusted for age, sex, BMI, educational status, family history of diabetes, smoking status, snacking between meals, active and sedentary lifestyle score and following a special diet at baseline. ${ }^{23}$ Adjusted for age, sex, educational level, baseline BMI, physical activity, smoking status, alcohol intake, number of 24-h dietary records, energy intake, Food Standards Agency nutrient profiling system dietary index score and family history of T2DM. ${ }^{24}$ Adjusted for age, sex and BMI. ${ }^{25}$ Adjusted for age, sex, energy intake without alcohol, number of 24-h dietary records, smoking status, educational level, physical activity, height, BMI, alcohol intake and family history of cancers (and for breast cancer outcome, additionally adjusted for menopausal status, hormonal treatment for menopause, oral contraception, and number of children). ${ }^{26}$ Adjusted for age and sex. ${ }^{27}$ Adjusted for age, sex, geographical region, education, alcohol intake, smoking status, BMI, total energy intake and location. ${ }^{28}$ Adjusted for age, sex, income level, education level, marital status, residence, BMI, physical activity, smoking status, energy intake, season of food records and time between food record and functional gastrointestinal disorders questionnaire. ${ }^{29}$ Adjusted for age, cohort and calendar year. ${ }^{30}$ Adjusted for age, sex, BMI, marital status, educational level, occupational categories, household income per consumption unit, residential area, number of 24-h dietary records, inclusion month, energy intake without alcohol, alcohol intake, smoking status and physical activity. ${ }^{31}$ Adjusted for sex, age and year of entrance to the cohort. ${ }^{32}$ Adjusted for sex, age and total energy intake. ${ }^{33}$ Adjusted for age, sex, BMI, smoking status, alcohol consumption status, education levels, employment status, household income, physical activity, depression symptoms, family history of disease (including cardiovascular disease, hypertension, hyperlipidaemia and diabetes), hypertension, hyperlipidaemia, diabetes and metabolic syndrome. ${ }^{34}$ Adjusted for sex, group status in the early phase (intervention and control), family income, pre-pregnancy BMI child birth weight and BMI z-scores at 3 years. ${ }^{35}$ Adjusted for age and sex. ${ }^{36}$ Crude model. ${ }^{37}$ Adjusted for baseline age, sex and BMI. * $95 \%$ credible intervals. 
Table 3. Prospective studies adjusting for fat, added sugar/carbohydrate and sodium content.

\begin{tabular}{|c|c|c|c|c|}
\hline Author, Year & Outcome & Method of Analysis & Diet Adjustment & Effect Estimate $(95 \% \mathrm{CI})$ \\
\hline Rico-Campa 2019 [103] & All-cause mortality & HR 1st vs. 4th quartile & SFA, sodium, added sugar and TFA & $1.69(1.12,2.56)$ \\
\hline \multirow[t]{3}{*}{ Bonaccio 2021 [105] } & All-cause mortality & HR 1st vs. 4th quartile & $\begin{array}{l}\text { SFA, sodium, sugar, cholesterol and } \\
\text { energy intake }\end{array}$ & $1.28(1.09,1.49)$ \\
\hline & CVD mortality & HR 1st vs. 4th quartile & $\begin{array}{l}\text { SFA, sodium, sugar, cholesterol and } \\
\text { energy intake }\end{array}$ & $1.56(1.19,2.03)$ \\
\hline & IHD/cerebrovascular mortality & HR 1st vs. 4th quartile & $\begin{array}{l}\text { SFA, sodium, sugar, cholesterol and } \\
\text { energy intake }\end{array}$ & $1.33(0.94,1.90)$ \\
\hline \multirow[t]{3}{*}{ Beslay 2020 [106] } & BMI change $\left(\mathrm{kg} / \mathrm{m}^{2}\right)$ & Beta per $10 \%$ increase in UPF & SFA, sodium, sugar and fibre & $0.02(0.01,0.02)$ \\
\hline & Overweight & HR per $10 \%$ increase in UPF & SFA, sodium, sugar and fibre & $1.10(1.08,1.13)$ \\
\hline & Obesity & HR per $10 \%$ increase in UPF & SFA, sodium, sugar and fibre & $1.10(1.06,1.14)$ \\
\hline \multirow[t]{3}{*}{ Koniecnzna 2021 [109] } & Total fat mass (z-score) & Beta per $10 \%$ increase in UPF & $\begin{array}{l}\text { SFA, sodium, glycaemic index, TFA, } \\
\text { alcohol and fibre }\end{array}$ & $0.06(0.03,0.09)$ \\
\hline & Visceral fat mass (z-score) & Beta per $10 \%$ increase in UPF & $\begin{array}{l}\text { SFA, sodium, glycaemic index, TFA, } \\
\text { alcohol and fibre }\end{array}$ & $0.06(0.01,0.10)$ \\
\hline & Android:gynoid fat ratio (z-score) & Beta per $10 \%$ increase in UPF & $\begin{array}{l}\text { SFA, sodium, glycaemic index, TFA, } \\
\text { alcohol and fibre }\end{array}$ & $0.02(-0.02,0.07)$ \\
\hline \multirow[t]{3}{*}{ Srour 2019 [117] } & All CVD & HR per $10 \%$ increase in UPF & SFA, sodium and sugar & $1.13(1.05,1.20)$ \\
\hline & Coronary heart disease & HR per $10 \%$ increase in UPF & SFA, sodium and sugar & $1.14(1.03,1.26)$ \\
\hline & Cerebrovascular disease & HR per $10 \%$ increase in UPF & SFA, sodium and sugar & $1.12(1.02,1.22)$ \\
\hline \multirow[t]{3}{*}{ Zhong 2021 [119] } & CVD mortality & HR 1st vs. 5th quintile & SFA, sodium and added sugar & $1.48(1.34,1.63)$ \\
\hline & Heart disease mortality & HR 1st vs. 5th quintile & SFA, sodium and added sugar & $1.65(1.47,1.85)$ \\
\hline & Cerebrovascular disease mortality & HR 1st vs. 5 th quintile & SFA, sodium and added sugar & $0.93(0.74,1.17)$ \\
\hline Srour 2020 [124] & T2DM & HR per $10 \%$ increase in UPF & SFA, sodium, sugar and fibre & $1.19(1.09,1.30)$ \\
\hline \multirow[t]{4}{*}{ Fiolet 2018 [126] } & All cancers & HR per $10 \%$ increase in UPF & Lipids, sodium and carbohydrates & $1.12(1.07,1.18)$ \\
\hline & Breast cancer & HR per $10 \%$ increase in UPF & Lipids, sodium and carbohydrates & $1.11(1.01,1.21)$ \\
\hline & Prostate cancer & HR per $10 \%$ increase in UPF & Lipids, sodium and carbohydrates & $0.98(0.83,1.16)$ \\
\hline & Colorectal cancer & HR per $10 \%$ increase in UPF & Lipids, sodium and carbohydrates & $1.16(0.95,1.42)$ \\
\hline \multirow[t]{4}{*}{ Chang 2021 [115] } & BMI $\left(\mathrm{kg} / \mathrm{m}^{2}\right) /$ year & Beta 1st vs. 5th quintile & SFA, sodium, sugar and fibre & $0.07(0.04,0.08)$ \\
\hline & Fat mass index $\left(\mathrm{kg} / \mathrm{m}^{2}\right) /$ year & Beta 1st vs. 5th quintile & SFA, sodium, sugar and fibre & $0.03(0.01,0.05)$ \\
\hline & Lean mass index $\left(\mathrm{kg} / \mathrm{m}^{2}\right) /$ year & Beta 1st vs. 5th quintile & SFA, sodium, sugar and fibre & $0.005(-0.007,0.010)$ \\
\hline & Body fat percentage $(\%) /$ year & Beta 1st vs. 5th quintile & SFA, sodium, sugar and fibre & $0.002(-0.05,0.05)$ \\
\hline
\end{tabular}

SFA, saturated fatty acids; TFA, trans fatty acids; HR, hazard ratio; CVD, cardiovascular disease; IHD, ischemic heart disease; BMI, body mass index; T2DM, type 2 diabetes mellitus. 
Table 4. Prospective studies adjusting for dietary pattern.

\begin{tabular}{|c|c|c|c|c|}
\hline Author, Year & Outcome & Method of Analysis & Diet Adjustment & Effect Estimate $(95 \% \mathrm{CI})$ \\
\hline \multirow[t]{2}{*}{ Schnabel 2019 [102] } & All-cause mortality & HR per $10 \%$ increase in UPF & \multirow{2}{*}{$\begin{array}{c}\text { French dietary guidelines } \\
\text { French dietary guidelines and Western dietary } \\
\text { pattern }\end{array}$} & $1.14(1.04,1.27)$ \\
\hline & All-cause mortality & HR per $10 \%$ increase in UPF & & $1.19(1.05,1.35)$ \\
\hline Rico-Campa 2019 [103] & All-cause mortality & HR 1st vs. 4th quartile & Mediterranean dietary pattern & $1.58(1.10,2.28)$ \\
\hline \multirow[t]{2}{*}{ Kim 2019 [104] } & All-cause mortality & P-trend & Dietary quality score & $p$-trend only $0.001^{1}$ \\
\hline & CVD mortality & P-trend & Dietary quality score & $p$-trend only $0.540^{1}$ \\
\hline \multirow{5}{*}{ Bonaccio 2021 [105] } & All-cause mortality & HR 1st vs. 4th quartile & Mediterranean dietary pattern & $1.26(1.09,1.46)$ \\
\hline & $\begin{array}{l}\text { Other cause mortality (exc. CVD } \\
\text { and cancer) }\end{array}$ & HR 1st vs. 4th quartile & Mediterranean dietary pattern & $1.26(0.94,1.69)$ \\
\hline & CVD mortality & HR 1st vs. 4th quartile & Mediterranean dietary pattern & $1.58(1.23,2.03)$ \\
\hline & IHD/cerebrovascular mortality & HR 1st vs. 4th quartile & Mediterranean dietary pattern & $1.52(1.10,2.09)$ \\
\hline & Cancer mortality & HR 1st vs. 4th quartile & Mediterranean dietary pattern & $0.97(0.77,1.22)$ \\
\hline \multirow{3}{*}{ Beslay 2020 [106] } & BMI change $\left(\mathrm{kg} / \mathrm{m}^{2}\right)$ & Beta per $10 \%$ increase in UPF & Healthy and Western dietary patterns & $0.02(0.01,0.02)$ \\
\hline & Overweight & HR per $10 \%$ increase in UPF & Healthy and Western dietary patterns & $1.10(1.07,1.13)$ \\
\hline & Obesity & HR per $10 \%$ increase in UPF & Healthy and Western dietary patterns & $1.11(1.07,1.15)$ \\
\hline Li 2021 [108] & Overweight/obesity & OR none vs. $\geq 50 \mathrm{~g} /$ day & Traditional and modern dietary patterns & $1.45(1.21,1.74)^{2}$ \\
\hline \multirow{3}{*}{ Koniecnzna 2021 [109] } & Total fat mass (z-score) & Beta per $10 \%$ increase in UPF & Mediterranean dietary pattern adherence & $0.06(0.02,0.09)$ \\
\hline & Visceral fat mass (z-score) & Beta per $10 \%$ increase in UPF & Mediterranean dietary pattern adherence & $0.06(0.01,0.10)$ \\
\hline & Android:gynoid fat ratio (z-score) & Beta per $10 \%$ increase in UPF & Mediterranean dietary pattern adherence & $0.02(-0.02,0.06)$ \\
\hline Sandoval-Insausti 2020 [110] & Abdominal obesity & OR 1st vs. 3rd tertile & $\begin{array}{l}\text { Mediterranean dietary pattern, fibre and very long } \\
\text { chain omega-3 fatty acid intake }\end{array}$ & $1.61(1.01,2.56)$ \\
\hline \multirow[t]{3}{*}{ Cordova 2021 [111] } & Weight gain $(\mathrm{kg})$ & Beta per 1SD increase in UPF/day & Mediterranean dietary pattern & $0.118(0.085,0.151)$ \\
\hline & Overweight/obesity & RR per 1SD increase in UPF/day & Mediterranean dietary pattern & $1.05(1.04,1.06)$ \\
\hline & Obesity & RR per 1SD increase in UPF/day & Mediterranean dietary pattern & $1.05(1.03,1.07)$ \\
\hline \multirow[t]{3}{*}{ Leone 2021 [114] } & Gestational diabetes pooled & OR 1st vs. 3rd tertile & Mediterranean dietary pattern & $1.10[0.74,1.65)$ \\
\hline & Gestational diabetes $<30$ & OR 1st vs. 3rd tertile & Mediterranean dietary pattern & $0.89[0.53,1.47)$ \\
\hline & Gestational diabetes $\geq 30$ & OR 1st vs. 3rd tertile & Mediterranean dietary pattern & $2.06(1.05,4.06)$ \\
\hline
\end{tabular}


Table 4. Cont.

\begin{tabular}{|c|c|c|c|c|}
\hline Author, Year & Outcome & Method of Analysis & Diet Adjustment & Effect Estimate (95\%CI) \\
\hline Costa $2021[116]$ & Fat mass index $\left(\mathrm{kg} / \mathrm{m}^{2}\right)$ & $\begin{array}{c}\text { Beta } / 100 g \text { daily increase in UPF } \\
\text { intake }\end{array}$ & $\begin{array}{l}\text { Unprocessed or minimally processed foods, } \\
\text { processed culinary ingredients and processed foods } \\
\text { intake }\end{array}$ & $0.14(0.13,0.15)$ \\
\hline \multirow[t]{3}{*}{ Srour 2019 [117] } & All CVD & HR per $10 \%$ increase in UPF & Healthy dietary pattern & $1.11(1.03,1.19)$ \\
\hline & Coronary heart disease & HR per $10 \%$ increase in UPF & Healthy dietary pattern & $1.11(1.00,1.23) p=0.04$ \\
\hline & Cerebrovascular disease & HR per $10 \%$ increase in UPF & Healthy dietary pattern & $1.10(1.00,1.20) p=0.04$ \\
\hline \multirow[t]{4}{*}{ Juul $2021[118]$} & Overall CVD & HR per serving UPF/day & Dietary Guidelines Adherence Index (DGAI) 2010 & $1.04(1.01,1.07)$ \\
\hline & CVD mortality & HR per serving UPF/day & Dietary Guidelines Adherence Index (DGAI) 2010 & $1.09(1.02,1.16)$ \\
\hline & Incident hard CVD & HR per serving UPF/day & Dietary Guidelines Adherence Index (DGAI) 2010 & $1.06(1.02,1.11)$ \\
\hline & Hard coronary heart disease & HR per serving UPF/day & Dietary Guidelines Adherence Index (DGAI) 2010 & $1.09(1.03,1.15)$ \\
\hline \multirow[t]{3}{*}{ Zhong 2021 [119] } & CVD mortality & HR 1st vs. 5th quintile & Healthy Eating Index (HEI) 2005 & $1.48(1.35,1.63)$ \\
\hline & Heart disease mortality & HR 1st vs. 5th quintile & Healthy Eating Index (HEI) 2005 & $1.67(1.49,1.86)$ \\
\hline & Cerebrovascular disease mortality & HR 1st vs. 5th quintile & Healthy Eating Index (HEI) 2005 & $0.94(0.75,1.16)$ \\
\hline Llavero-Valero 2021 [123] & T2DM & HR 1st vs. 3rd tertile & Mediterranean dietary pattern & $1.50(1.02,2.21)$ \\
\hline Srour 2020 [124] & $\mathrm{T} 2 \mathrm{DM}$ & HR per $10 \%$ increase in UPF & Healthy and Western dietary patterns & $1.13(1.04,1.24)$ \\
\hline Zhang 2021 [125] & NAFLD & HR 1st vs. 4th quartile & Healthy diet score & $1.19(1.08,1.31)^{3}$ \\
\hline \multirow[t]{4}{*}{ Fiolet 2018 [126] } & All cancers & HR per $10 \%$ increase in UPF & Western dietary pattern & $1.12(1.06,1.18)$ \\
\hline & Breast cancer & HR per $10 \%$ increase in UPF & Western dietary pattern & $1.11(1.02,1.22)$ \\
\hline & Prostate cancer & HR per $10 \%$ increase in UPF & Western dietary pattern & $0.98(0.83,1.15)$ \\
\hline & Colorectal cancer & HR per $10 \%$ increase in UPF & Western dietary pattern & $1.13(0.92,1.38)$ \\
\hline Vasseur 2021 [127] & IBD & RR 1st vs. 3rd tertile & Healthy dietary pattern & $1.44(0.70,2.94)^{4}$ \\
\hline \multirow[t]{3}{*}{ Narula 2021 [128] } & IBD & HR $<1$ vs. $\geq 5$ servings UPF/day & Alternate Healthy Eating Index (AHEI) 2010 & $1.92(1.28,2.90)$ \\
\hline & Crohn's disease & HR $<1$ vs. $\geq 5$ servings UPF / day & Alternate Healthy Eating Index (AHEI) 2010 & $4.90(1.78,13.45)$ \\
\hline & Ulcerative Colitis & HR $<1$ vs. $\geq 5$ servings UPF/day & Alternate Healthy Eating Index (AHEI) 2010 & $1.52(0.96,2.41)$ \\
\hline \multirow[t]{2}{*}{ Lo $2021[130]$} & Crohn's disease & HR 1st vs. 4th quartile & Alternate Healthy Eating Index (AHEI) 2010 & $1.70(1.23,2.35)^{5}$ \\
\hline & Ulcerative Colitis & HR 1st vs. 4th quartile & Alternate Healthy Eating Index (AHEI) 2010 & $1.20(0.91,1.58)^{5}$ \\
\hline \multirow[t]{4}{*}{ Schnabel 2018 [129] } & Irritable bowel syndrome & OR 1st vs. 4th quartile & French dietary guidelines & $1.25(1.12,1.39)$ \\
\hline & Functional Constipation & OR 1st vs. 4th quartile & French dietary guidelines & $0.98(0.85,1.12)$ \\
\hline & Functional diarrhoea & OR 1st vs. 4th quartile & French dietary guidelines & $0.92(0.69,1.24)$ \\
\hline & Functional dyspepsia & OR 1st vs. 4th quartile & French dietary guidelines & $1.25(1.05,1.47)$ \\
\hline
\end{tabular}


Table 4. Cont.

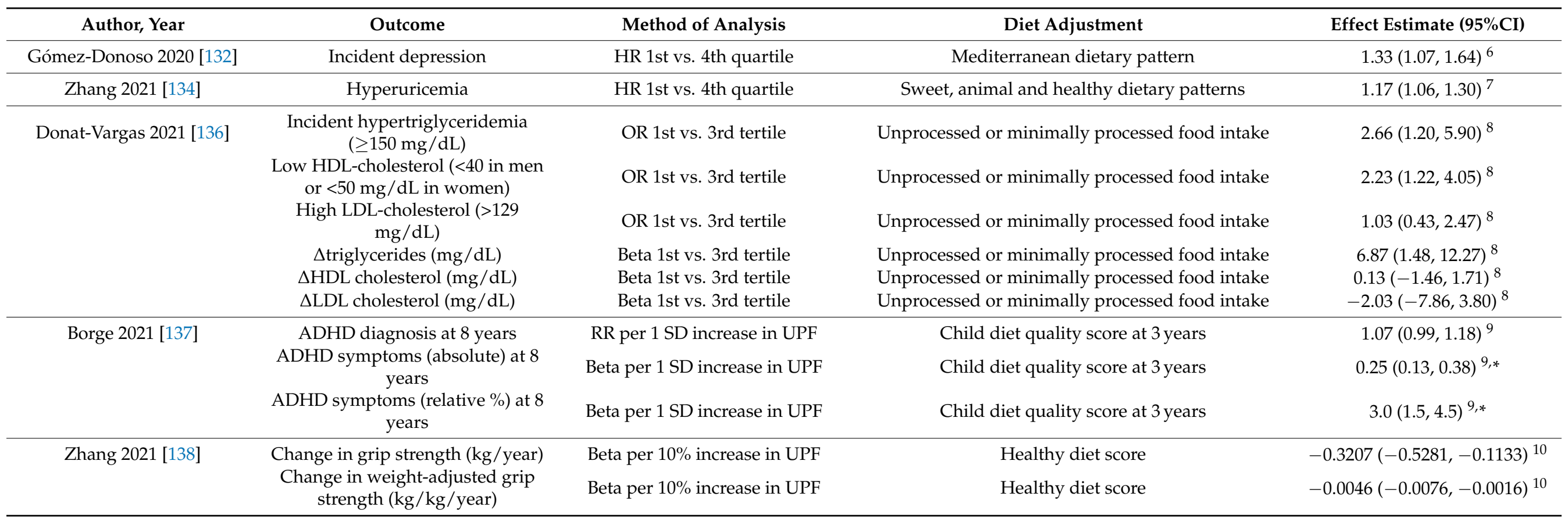

OR, odds ratio; HR, hazard ratio; RR, relative risk; ADHD, attention deficit hyperactivity disorder; $C V D$, cardiovascular disease; IHD, ischemic heart disease; BMI, body mass index; T2DM, type 2 diabetes mellitus; IBD, inflammatory bowel disease; NAFLD, non-alcoholic fatty liver disease. ${ }^{1}$ Further adjusted for body mass index, hypertension status, total cholesterol, and estimated glomerular filtration rate. ${ }^{2}$ Further adjusted for fat intake, income, education, urbanisation, alcohol, smoking and physical activity. ${ }^{3}$ Further adjusted for total energy intake, smoking status, alcohol drinking status, educational level, occupation, monthly household income, physical activity, family history of disease (including cardiovascular disease, hypertension, hyperlipidaemia and diabetes) and depressive symptoms. ${ }^{4}$ Further adjusted for income level, education level, marital status, residence, BMI, physical activity, smoking status, hormon contraception, number of 24 -h dietary records and energy intake. ${ }^{5}$ Further adjusted for race, family history of IBD, smoking, BMI, physical activity, total energy intake, stature regular NSAIDs use, oral contraceptives use, and menopausal hormone therapy. ${ }^{\circ}$ Further adjusted for baseline BMI, total energy intake, physical activity, smoking status, marital status, living alone, employment status, working hours per week, health-related career, years of education and baseline self-perception of competitiveness, anxiety and dependence levels. Further adjusted for energy intake. ${ }^{8}$ Further adjusted for fibre intake, total energy intake, educational level, marital status, smoking status, BMI, physical activity, alcohol consumption, number of medications and number of chronic conditions. ${ }^{9}$ Further adjusted for maternal pre-pregnancy BMI, maternal education, smoking and alcohol intake during pregnancy, maternal symptoms of depression and ADHD, maternal age, parity, child sex and childbirth quarter. ${ }^{10}$ Further adjusted for smoking status, alcohol drinking status, education level, employment, monthly household income, physical activity, family history of disease (including CVD, hypertension, hyperlipidaemia and diabetes), depressive symptoms, hypertension, hyperlipidaemia, diabetes, total energy intake, dietary supplement use, total protein intake and milk intake. * $95 \%$ credible intervals. 
Within the NutriNet-Santé cohort, several studies have performed dietary adjustments for the associations between UPF intake and all-cause mortality, CVD, overweight/obesity incidence, T2DM, cancer and functional gastrointestinal disorders [102,106,117,124,126,127,129]. Schnabel et al. found a 15\% (95\% confidence interval: 1.04, 1.27) increased risk of all-cause mortality per $10 \%$ increase in UPF intake in the diet [102]. Adjusting for French dietary guideline adherence or for both French dietary guideline adherence and for Western dietary pattern still resulted in each 10\% increment in UPF intake being associated with a 14\% (1.04, $1.27)$ or $19 \%(1.05,1.35)$ increased risk, respectively, of all-cause mortality [102].

Srour et al. reported a $12 \%(1.05,1.20), 13 \%(1.02,1.24)$ and $11 \%(1.01,1.21)$ increased risk of CVD, coronary heart disease (CHD) and cerebrovascular disease, respectively, per $10 \%$ increase in UPF in the diet [117]. Multiple dietary adjustments did not alter these risk estimates. First, adjusting for saturated fat, sodium and added sugar intake resulted in a $13 \%(1.05,1.20), 14 \%(1.03,1.26)$ and $12 \%(1.02,1.22)$ increased risk of CVD, CHD and cerebrovascular disease, respectively [117]. Second, adjusting instead for a healthy dietary pattern still resulted in an 11\% $(1.03,1.19), 11 \%(1.00,1.23, p=0.04)$ and $10 \%(1.00,1.20$, $p=0.04)$ increased risk of CVD, CHD and cerebrovascular disease, respectively [117]. Third, adjusting for intakes of sugary products, red and processed meat, salty snacks, beverages, fats and sauces also still resulted in a $12 \%(1.04,1.20), 12 \%(1.01,1.24)$ and $11 \%(1.01,1.22)$ increased risk of CVD, CHD and cerebrovascular disease, respectively, per $10 \%$ increase in UPF in the diet [117].

In a separate study, Srour et al. reported a 15\% $(1.06,1.25)$ increased risk of T2DM with each $10 \%$ increase in UPF in the diet, which included adjustment for dietary quality using the FSA-NPS-DI [124]. Again, subsequent dietary adjustments did not alter the increased risk of T2DM. A 10\% increase in UPF in the diet was still associated with a 19\% $(1.09,1.30)$ increased risk when further adjusting for saturated fat, sodium, sugar and dietary fibre intake, a 13\% $(1.04,1.24)$ increased risk after adjusting for healthy and Western dietary patterns, and a $14 \%(1.04,1.25)$ increased risk after adjusting for intakes of red and processed meat, sugary drinks, fruits and vegetables, whole grains, nuts, and yogurt in place of the FSA-NPS-DI adjustment [124]. Srour et al. also adjusted for absolute amounts of unprocessed or minimally processed food intake, which few studies have performed to date. This adjustment also did not alter the increased risk of T2DM (hazard ratio (HR) per $100 \mathrm{~g} /$ day increase in UPF intake: $1.05(1.02,1.08)$ [124].

Fiolet et al. reported a $12 \%(1.06,1.18)$ and $11 \%(1.02,1.22)$ increased risk of all cancer and breast cancer, respectively, per 10\% increase in UPF in the diet [126]. Adjustment for lipids (including fat), sodium and carbohydrate intake had no impact on the risk of all cancer (HR: $1.12(1.07,1.18)$ ) or breast cancer (HR: $1.11(1.01,1.21))$ per $10 \%$ increase in UPF in the diet, respectively [126]. Adjustment instead for Western dietary pattern also did not change the $12 \%(1.06,1.18)$ and $11 \%(1.02,1.22)$ increased risks [126].

Beslay et al. reported a greater BMI gain $\left(\beta: 0.02 \mathrm{~kg} / \mathrm{m}^{2}(0.01,0.02)\right)$ and increased risk of overweight (HR: $1.11(1.08,1.14)$ ) or obesity (HR: $1.09(1.05,1.13))$, per $10 \%$ increase in UPF in the diet [106]. Adjusting for healthy and Western dietary patterns did not alter the greater BMI gain $\left(\beta: 0.02 \mathrm{~kg} / \mathrm{m}^{2}(0.01,0.02)\right)$, or increased risk of overweight (HR: 1.10 (1.07, $1.13)$ ) or obesity (HR: $1.11(1.07,1.15))$, and neither did adjustment for saturated fat, sugar, sodium and dietary fibre intake, which also resulted in a greater BMI gain $\left(\beta: 0.02 \mathrm{~kg} / \mathrm{m}^{2}\right.$ $(0.01,0.02))$, and increased risk of overweight (HR: $1.10(1.08,1.13))$ or obesity (HR: 1.10 $(1.06,1.14)$, per $10 \%$ increase in UPF intake [106].

Schnabel et al. identified an increased risk of irritable bowel syndrome (IBS) (odds ratio (OR): $1.24(1.12,1.38)$ ) and functional dyspepsia (OR: $1.26(1.07,1.48))$ when comparing the highest vs. lowest quartiles of UPF intake [129]. Adjustment for adherence to French dietary guidelines did not alter the increased risk of IBS (OR: $1.25(1.12,1.39)$ ) or functional dyspepsia (OR: 1.25 (1.05, 1.47)) across extreme quartiles of UPF intake [129].

Four studies within the Seguimiento Universidad de Navarra (SUN) cohort have adjusted for fat, added sugar and sodium intake, or for dietary pattern. Rico-Campa et al. demonstrated that the highest vs. lowest quartile of UPF intake was associated with a 
$62 \%(1.13,2.33)$ increased risk of all-cause mortality [103]. Adjustment for saturated and trans fats, added sugar and sodium intake still resulted in a $69 \%(1.12,2.56)$ increased risk of all-cause mortality. A 58\% $(1.10,2.28)$ increased risk still remained after adjusting for Mediterranean diet pattern adherence instead [103].

Llavero-Valero et al. reported that the highest vs. lowest tertile of UPF intake was associated with a 53\% $(1.06,2.22)$ increased risk of T2DM, which was unaltered (HR: 1.50 $(1.02,2.21))$ after adjusting for Mediterranean diet pattern adherence [123].

Gómez-Donoso et al. found a $41 \%(1.15,1.73)$ increased risk of incident depression in the highest vs. lowest quartile of UPF intake, which was still associated with a 33\% $(1.07,1.64)$ higher risk of incident depression after further adjustment for other covariates, including Mediterranean diet pattern adherence [132].

Leone et al. identified an increased risk of gestational diabetes in females aged 30 and over (OR 1st vs. 3rd tertile: $2.05(1.03,4.07))$, which was unaltered after adjustment for Mediterranean diet pattern adherence (OR 1st vs. 3rd tertile: $2.06(1.05,4.06))$ [114].

In the US Third National Health and Nutrition Examination Survey (NHANES III) cohort, there was a $31 \%(1.09,1.58)$ increased risk of all-cause mortality in the highest vs. lowest quartile of UPF intake, which remained significant after further adjustment for dietary quality score using the HEI-2000 ( $p$-trend = 0.001) [104]. However, diet-adjusted risk estimates were not provided.

In the Italian Moli-sani cohort, the highest vs. lowest quartile of UPF intake was associated with a $32 \%(1.15,1.53)$ higher risk of all-cause mortality, $65 \%(1.29,2.11)$ higher risk of CVD mortality, and a $63 \%(1.19,2.25)$ higher risk of ischemic heart disease (IHD)/cerebrovascular mortality [105]. Adjusting for saturated fat, sugar, sodium and dietary cholesterol intake resulted in a $28 \%(1.09,1.49), 56 \%(1.19,2.03)$ and $33 \%(0.94$, 1.90) increased risk of all-cause, CVD and IHD/cerebrovascular mortality, respectively, in the highest vs. lowest quartile of UPF intake. Bonaccio et al. also individually adjusted for saturated fat, sugar, sodium and dietary cholesterol in turn, with UPF intake remaining significantly associated with all-cause, CVD and IHD/cerebrovascular mortality in all adjustments, except for sugar intake and IHD/cerebrovascular mortality (HR: 1.37 $(0.98,1.90))$. Adjusting instead for Mediterranean diet pattern adherence resulted in a $26 \%(1.09,1.46), 58 \%(1.23,2.03)$ and $52 \%(1.10,2.09)$ increased risk of all-cause, CVD and IHD/cerebrovascular mortality [105].

In the Framingham Offspring cohort, each additional serving of UPF per day was associated with a $5 \%(1.02,1.08), 9 \%(1.02,1.16), 7 \%(1.03,1.12)$ and $9 \%(1.04,1.15)$ increased risk of overall CVD, CVD mortality, hard CVD and hard coronary heart disease, respectively [118]. Further adjustment for diet quality using the DGAI-2010 still resulted in a 4\% $(1.01,1.07), 9 \%(1.02,1.16), 6 \%(1.02,1.11)$ and $9 \%(1.03,1.15)$ increased risk of overall CVD, CVD mortality, hard CVD and hard coronary heart disease [118].

In the US Prostate, Lung, Colorectal, and Ovarian Cancer Screening Trial cohort, the highest vs. lowest quintile of UPF intake was associated with a 50\% $(1.36,1.64)$ increased risk of CVD mortality, and a 68\% $(1.50,1.87)$ increased risk of heart disease mortality [119]. Multiple dietary adjustments did not alter this risk; adjustment for saturated fat, added sugar and sodium resulted in a $48 \%(1.34,1.63)$ and $65 \%(1.47,1.85)$ increased risk of CVD mortality and heart disease mortality, adjustment for diet quality using HEI-2005 resulted in a $48 \%(1.35,1.63)$ and $67 \%(1.49,1.86)$ increased risk of CVD mortality and heart disease mortality, and adjustment instead for red meat, processed meat, whole grains, fruit, vegetables, fibre and dairy intake also still resulted in a $49 \%(1.35,1.64)$ and $66 \%(1.48,1.86)$ increased risk of CVD mortality and heart disease mortality, respectively [119].

In the European Prospective Investigation into Cancer and Nutrition (EPIC) cohort, each additional standard deviation (SD) increment in UPF intake per day was associated with a $0.12 \mathrm{~kg}(0.09,0.15)$ greater increase in weight over 5 years of follow-up, which was unaltered after further adjusting for Mediterranean diet score $(\beta: 0.12 \mathrm{~kg} / 5$ years $(0.09$, 0.15)) [111]. In sensitivity analyses of fully adjusted models including Mediterranean diet adherence, UPF intake was associated with a higher risk of overweight/obesity (relative 
risk (RR): $1.05(1.04,1.06))$ and obesity (RR: $1.05(1.03,1.07))$ per 1SD increase in UPF per day. This corresponded to a $15 \%(1.11,1.19)$ higher risk of overweight/obesity in participants with normal weight and a $16 \%(1.09,1.23)$ higher risk of obesity in participants with overweight at baseline, when comparing the highest vs. lowest quintiles of UPF intake [111].

In the China Nutrition and Health Survey (CNHS), consuming $\geq 50 \mathrm{~g}$ of UPF per day was associated with an increased risk of overweight/obesity (OR: $1.85(1.58,2.17)$ ) and central obesity (OR: $2.04(1.79,2.33))$, when compared to no UPF intake. Adjustment for traditional and modern dietary patterns did not alter the increased risks (overweight/obesity, OR: 1.45 (1.21, 1.74), central obesity, OR: $1.50(1.29,1.74))$ [108].

In the Seniors Study on Nutrition and Cardiovascular Risk in Spain (Seniors-ENRICA-1), Sandoval-Insausti et al. found an increased risk of abdominal obesity (OR: $1.62(1.04,2.54)$ in the highest vs. lowest tertile of UPF intake, which was unaltered after adjustment for Mediterranean diet adherence and fibre and omega-3 fatty acid intake (OR: $1.61(1.01,2.56))$ [110].

Donat-Vargas et al. identified an increased risk of hypertriglyceridaemia (OR: 2.00 $(1.04,3.85))$ and low-HDL cholesterol (OR: $2.04(1.22,3.41))$, as well as a significant increase in blood triglycerides $(\beta: 6.11 \mathrm{mg} / \mathrm{dL}(1.30,10.91))$ when comparing the highest vs. lowest tertile of UPF intake [136]. Adjustment for unprocessed or minimally processed food intake did not alter the increased risk of hypertriglyceridaemia (OR: $2.66(1.20,5.90)$ ), low-HDL cholesterol (OR: $2.23(1.22,4.05))$ or change in blood triglycerides $(\beta: 6.87 \mathrm{mg} / \mathrm{dL}$ $(1.48,12.27))$ [136].

In the Pelotas-Brazil 2004 Birth Cohort, Costa et al. found a $0.09 \mathrm{~kg} / \mathrm{m}^{2}(0.07,0.10)$ greater gain in FMI from ages 6 to 11, per $100 \mathrm{~g}$ daily increase in UPF intake [116]. Adjustment for other NOVA food groups (minimally processed and processed food, and processed culinary ingredients intake) significantly increased the associated FMI gain to $0.14 \mathrm{~kg} / \mathrm{m}^{2}(0.13,0.15)$ from age 6 to 11, per $100 \mathrm{~g}$ daily increase in UPF intake [116].

In the Avon Longitudinal Study of Parents and Children (ALSPAC) cohort, the highest vs. lowest quintile of UPF intake was associated with a $0.06 \mathrm{~kg} / \mathrm{m}^{2}(0.04,0.08)$ and $0.03 \mathrm{~kg} / \mathrm{m}^{2}(0.01,0.05)$ greater yearly increase in BMI and FMI, respectively, from the age of 7 to 24 [115]. Adjustment for saturated fat, sugar, sodium and fibre intake did not alter the association between UPF intake and increases in BMI $\left(\beta: 0.07 \mathrm{~kg} / \mathrm{m}^{2} /\right.$ year $\left.(0.04,0.08)\right)$ or FMI $\left(\beta: 0.03 \mathrm{~kg} / \mathrm{m}^{2} /\right.$ year $\left.(0.01,0.05)\right)[115]$.

Koniecnzna et al. conducted a prospective analysis of the PREDIMED-Plus trial over the course of 12 months. Each 10\% increment in UPF intake was associated with increases in total $(\beta$ : $0.09(0.06,0.13))$ and visceral $(\beta: 0.09(0.05,0.13))$ fat mass z-scores. Adjusting for overall repeated measures of saturated and trans fat, sodium, glycaemic index, alcohol and fibre intake across the 12 month study did not alter the significant association between UPF intake and increases in total $(\beta: 0.06(0.03,0.09)$ and visceral $(\beta: 0.06(0.01,0.10))$ fat mass z-scores per 10\% increase in daily UPF intake [109]. Adjusting instead for overall repeated measures of Mediterranean diet pattern adherence across the 12 month study also did not alter the association between each $10 \%$ increment in UPF intake and increases in total $(\beta: 0.06(0.02,0.09))$ and visceral $(\beta: 0.06(0.01,0.10))$ fat mass z-scores [109].

In the Tianjin Chronic Low-grade Systemic Inflammation and Health (TCLSIH) Cohort Study, the highest vs. lowest quartile of UPF intake was associated with a $17 \%(1.07,1.29)$ higher risk of non-alcoholic fatty liver disease (NAFLD) in the age, sex and BMI adjusted model. After adjustment for other confounders including for a healthy diet score based on fruit, vegetable, red meat and fish intake, the increased risk associated with the highest vs. lowest quintile of UPF intake was $19 \%(1.08,1.31)$ [125].

Zhang et al. found a $21 \%(1.10,1.33)$ increased risk of hyperuricaemia in the highest vs. lowest quartile of UPF intake, which was still associated with a 17\% $(1.06,1.30)$ increased risk of hyperuricaemia after adjustment for dietary pattern [134].

In a separate study, Zhang et al. reported that each $10 \%$ increment in UPF in the diet was associated with a $-0.30 \mathrm{~kg}(-0.50,-0.09)$ and $-0.0043 \mathrm{~kg} / \mathrm{kg}$ weight $(-0.0073$, -0.0014 ) yearly reduction in absolute and weight-adjusted grip strength, respectively [138]. 
Adjustment for further covariates including a healthy diet score (based on fruit, vegetable, unprocessed red meat and fish intake), dietary supplement use and protein and milk intake did not alter the association, with each $10 \%$ increment in UPF intake still associated with $-0.32 \mathrm{~kg}(-0.53,-0.11)$ and $-0.0046 \mathrm{~kg} / \mathrm{kg}$ weight $(-0.0076,-0.0016)$ yearly reductions in absolute and weight-adjusted grip strength, respectively [138].

In a combined analysis of the Nurses' Health Study, the Nurses' Health Study II and the Health Professionals Follow-up Study, Lo et al. found a $75 \%(1.29,2.35)$ increased risk of Crohn's disease in the highest vs. lowest quartile of UPF intake after adjusting for age, cohort and calendar year. The increased risk was unchanged after further covariate adjustments, including for diet quality defined by the AHEI-2010 (HR: 1.70 $(1.23,2.35))[130]$.

In the Prospective Urban Rural Epidemiology (PURE) cohort, Narula et al. identified an $82 \%(1.22,2.72)$ increased risk of inflammatory bowel disease (IBD) and a $450 \%(1.67$, 12.13) increased risk of Crohn's disease in those consuming five or more UPF servings per day, compared with those consuming less than one serving per day. Adjustment for AHEI-2010 still resulted in a $92 \%(1.28,2.90)$ increased risk of IBD and a $490 \%(1.78,13.45)$ increased risk of Crohn's disease [128].

In the Norwegian Mother, Father and Child Cohort Study, Borge et al. reported that each 1 SD increase in maternal UPF intake was associated with an increase in absolute $(0.38$ $(0.27,0.49))$ and relative $(4.5 \%(3.3,4.9))$ measures of child attention deficit hyperactivity disorder (ADHD) symptoms at age 8, using the Parent Rating Scale for Disruptive Behaviour Disorders [137]. Adjustment for child Diet Quality Index (based on diet diversity, diet quality and diet equilibrium [139]) did not alter the associated increase in absolute $(0.25(0.13,0.38))$ or relative $(3.0 \%(1.5,4.5))$ ADHD symptoms [137].

Three studies have considered the impact of diet quality and dietary pattern using alternative methods. In the ATTICA cohort, each additional weekly serving of UPF was associated with a $10 \%(1.02,1.21)$ increased risk of CVD. Kouvari et al. then performed sub-group analysis based on Mediterranean diet pattern adherence. Participants with moderate to high adherence to the Mediterranean diet had an attenuated $(8 \%(0.98,1.19))$ risk of CVD per weekly serving of UPF, whereas participants with low adherence to the Mediterranean diet had an even greater risk of $19 \%(1.12,1.25)$, per weekly serving of UPF [140].

Bonaccio et al. identified that diet quality (defined by the FSA-NPS-DI) was only significantly associated with all-cause mortality in high UPF consumers (HR per $1 \mathrm{SD}$ increase in FSA-NPS-DI: $1.14(1.05,1.25)$, but not in low UPF consumers (HR: 1.00 (0.93, 1.07) $(p$ for interaction $=0.034)$ in the Moli-sani cohort [141]. The interaction between diet quality and UPF intake was not significant for CVD mortality.

In the ENRICA study, the highest vs. lowest quartile of UPF intake had a $44 \%$ (1.01, 2.07) increased risk of all-cause mortality [91]. Instead of dietary adjustment, Blanco-Rojo et al. compared the highest vs. lowest intakes of nutrients from UPF intake, including total, saturated and trans fat, carbohydrates, sugar, sodium and fibre [91]. The nutrient content of UPFs was not associated with an increased mortality risk, except for trans fat (HR highest vs. lowest quartile: $1.39(1.00,1.92), p=0.047)$.

\subsection{Adjustment for Fat, Sodium, Carbohydrate and Dietary Pattern}

Two studies have simultaneously adjusted for fat, sodium and carbohydrate intake and for dietary pattern, which are reported in Supplementary Table S1. For cancer outcomes, Fiolet et al. adjusted for both intakes of lipids (including fat), sodium, and carbohydrates and Western dietary pattern, resulting in a $13 \%(1.07,1.18)$ and $11 \%(1.01,1.21)$ increased risk of all cancer and breast cancer per 10\% increase in UPF in the diet [126].

Adjibade et al. identified a $21 \%(1.15,1.27)$ higher risk of depressive symptoms per $10 \%$ increase in UPF in the diet in the NutriNet-Santé cohort [131]. After adjusting for intakes of lipids (including fat), sodium, and carbohydrates and for healthy and Western 
dietary patterns, the risk of depressive symptoms per $10 \%$ increase in UPF in the diet was still 22\% $(1.16,1.29)[131]$.

\subsection{Adjustment for Fat And/or Sugar and/or Sodium}

Some studies have adjusted for one or two components of fat and/or sugar and/or sodium intake, rather than all three components. One study adjusted for carbohydrate intake, rather than sugar intake [114]. These adjustments are reported in Supplementary Table S2. The significant associations between UPF intake and all-cause mortality, overweight or obesity, central obesity, T2DM, hypertension, gestational weight gain, neonatal anthropometrics and blood lipid profiles were unchanged following these dietary adjustments $[103,108,113,114,120,123,135,136]$.

\subsection{Adjustment for Other Dietary Components}

Other measures used for dietary adjustment are provided in Supplementary Table S3. Other dietary adjustments include for fried foods, fruit and vegetables, UPF soft drinks, multivitamin use and excluding bacon, sausage and processed meats from ultra-processed food intake. These adjustments had no impact on the association between higher intakes of UPF and risk of all-cause mortality, cancer, overweight/obesity, increased total and visceral fat mass, increased BMI and FMI, NAFLD, weight and waist circumference gain, adverse blood lipid profiles, grip strength decline, incident hypertension and renal function decline [103,104,106,107,109,111,112,115,121,122,125,126,133,136,138].

\subsection{Dietary Adjustments That Explain the Association between UPF Intake and} Health-Related Outcomes

To date, only two studies have performed dietary adjustments that explain the association between higher UPF intakes and adverse health-related outcomes. In the PREDIMEDPlus study, each $10 \%$ increase in UPF in the diet was associated with a 5\% $(0.00,0.09$, $p=0.031)$ increase in android:gynoid fat ratio z-score during 12 months of follow-up [109]. Adjusting for repeated measures of sodium, saturated and trans fat, alcohol, fibre and glycaemic index, or adjusting for repeated measures of Mediterranean Diet adherence during the 12-month follow-up period resulted in a non-significant association between UPF intake and android:gynoid fat ratio z-score [109].

In the Moli-sani cohort, the highest vs. lowest quartile of UPF intake had a $36 \%$ $(1.01,1.83)$ higher risk of other cause mortality (any mortality, excluding CVD and cancer). However, after adjusting for Mediterranean diet score, this became non-significant (1.26 $(0.94,1.69))$ [105]. As noted in Section 6.1, the increased risk of IHD/cerebrovascular mortality also became non-significant after adjusting for saturated fat, sugar, sodium and dietary cholesterol.

\subsection{Adjustment for Total Energy Intake}

An ultra-processed diet has been shown to increase energy intake in comparison with a minimally processed diet [49]. Energy intake may be a mediator of both nutritional aspects (high energy density and palatability), and of some ultra-processing aspects (a degraded food matrix influencing oro-sensory exposure and satiety) of UPFs. Adjustment for total daily energy intake is not only useful to control for measurement error in epidemiological dietary assessment to improve risk estimation of other dietary measures [142,143], but it can also provide information on the associated risk between UPF intake and adverse health outcomes, independent of energy intake [144].

Adjustment for energy intake can be achieved using several methods $[145,146]$. However, it has typically been performed by energy-adjusting the UPF independent variable, either via the residual method (regressing UPF intake onto total energy intake to produce residuals) or via the nutrient density method (usually as 'energy intake from UPFs/total energy intake', though 'total weight of UPFs/total food weight' has also been used to capture the non-nutritive aspects of UPFs) [146]. Total energy intake is then included 
as a covariate in the model [146]. Some studies instead use absolute UPF intake as the independent variable, and then include total energy intake in the model.

Table 5 presents the prospective cohort studies performing adjustments for total energy intake. Forty-seven studies have performed some form of energy adjustment across 131 models. 80 models demonstrate a significant association between energy-adjusted UPF intake and a health-related outcome. 6/6 models were significantly associated with all-cause mortality, 12/15 models were significantly associated with any CVD outcome, 3/3 models were significantly associated with T2DM, 15/17 models were significantly associated with adult weight gain/overweight/obesity, and 15/25 models with gestational or child anthropometrics. Twenty-one non-significant models with energy adjustment were from multiple models for child appetitive traits (eight; Vedovato et al. [99]), childhood anthropometrics and glucose profiles (six; Costa et al. [98]), child asthma and wheezing (four; Machado Azeredo et al. [101]) and childhood lipid profiles (three; Rauber et al. [95]). Four studies provided insufficient detail on energy adjustments [87,96,140,147].

\subsection{Prospective Studies Reporting Mediation Analyses}

Besides being included as a covariate within models, formal mediation analysis can be used to determine whether dietary components mediate the association between UPF intake and adverse health-related outcomes $[149,150]$. Few studies to date have performed mediation analyses between UPF intake, dietary components and health-related outcomes.

Bonaccio et al. examined the mediating role of nutrients and energy content on allcause mortality, CVD mortality and IHD/cerebrovascular mortality [105]. All dietary factors combined (sugar, saturated fat, dietary cholesterol, dietary sodium and energy content) significantly accounted for $41.3 \%((11.9 \%, 78.5 \%), p<0.001)$ of IHD/cerebrovascular mortality risk, but did not account for all-cause mortality $(12.8 \%(1.6 \%, 56.5 \%), p=0.14)$ or CVD mortality $(11.5 \%(1.5 \%, 53.3 \%), p=0.15)$ risk. Sugar content alone accounted for $23.2 \%((9.7 \%, 45.9 \%), p<0.001), 18.0 \%((7.2 \%, 38.4 \%), p=0.003)$ and $36.3 \%((13.8 \%, 67.0 \%)$, $p<0.001)$ ) of the associated risk between UPF intake and all-cause mortality, CVD mortality and IHD/cerebrovascular mortality, respectively. Saturated fat or sodium content did not account for any of the associated risks.

Fiolet et al. performed mediation analyses for sodium, total lipids, saturated fat, monounsaturated fat, polyunsaturated fat, carbohydrate and for Western dietary pattern, with all mediation effects for the association between UPF intake and overall cancer being less than $2 \%$ (all $p>0.05)$ [126].

Koniecnzna et al. found that repeated measures of saturated fat, trans fat and fibre explained 11-30\% of the associations between UPF intake and increases in measures of central and overall adiposity over 12 months of follow-up [109]. Repeated measures of sodium, total energy intake and glycaemic index did not mediate any of the associations.

Costa et al. identified that $58.2 \%\left(0.07 \mathrm{~kg} / \mathrm{m}^{2}(0.05,0.10)\right)$ of the association between UPF intake and the increase in FMI from age 6 to 11 in children was mediated by energy content, with the remaining $41.8 \%$ being either a direct effect of ultra-processing, or as a result of unmeasured variables [116].

Vedovato et al. showed that energy intake was a mediator between UPF intake at 4 years of age and the appetite traits, 'satiety responsiveness' and 'food fussiness', but not with 'food responsiveness', at age 7 [99].

Gomes et al. showed that the percentage of total energy derived from UPFs in the third trimester was associated with total energy intake in the third trimester, which was also associated with gestational weight gain in the third trimester [93]. 
Table 5. Prospective cohort studies adjusting for total energy intake.

\begin{tabular}{|c|c|c|c|c|}
\hline Author, Year & Outcome & Method of Analysis & Energy Adjustment & Effect \\
\hline Schnabel 2019 [102] & All-cause mortality & HR per $10 \%$ increase in UPF & UPF as $\%$ weight + adjusted for TEI & $1.15(1.04,1.27)^{1}$ \\
\hline \multirow[t]{2}{*}{ Rico-Campa 2019 [103] } & All-cause mortality & HR 1st vs. 4th quartile & Energy-adjusted UPF + adjusted for TEI & $1.62(1.13,2.33)^{2}$ \\
\hline & Cardiovascular deaths & HR 1st vs. 4th quartile & Energy-adjusted UPF + adjusted for TEI & $2.16(0.92,5.06)^{2}$ \\
\hline Blanco-Rojo 2019 [91] & All-cause mortality & HR 1st vs. 4th quartile & UPF as \% TEI & $1.44(1.01,2.07)^{3}$ \\
\hline \multirow[t]{2}{*}{ Kim 2019 [104] } & All-cause mortality & HR 1st vs. 4th quartile & UPF servings/day + adjusted for TEI & $1.31(1.09,1.58)^{4}$ \\
\hline & CVD mortality & HR 1st vs. 4th quartile & UPF servings/day + adjusted for TEI & $1.10(0.74,1.67)^{4}$ \\
\hline Romero Ferreiro 2021 [89] & All-cause mortality & HR per $10 \%$ increase in UPF & UPF as \% TEI + adjusted for TEI & $1.16(1.06,1.26)^{5}$ \\
\hline \multirow[t]{5}{*}{ Bonaccio 2021 [105] } & All-cause mortality & HR 1st vs. 4th quartile & $\begin{array}{c}\text { UPF as \% weight + adjusted for TEI and } \\
\text { energy content of UPFs }\end{array}$ & $1.35(1.15,1.58)^{6}$ \\
\hline & CVD mortality & HR 1st vs. 4th quartile & $\begin{array}{c}\text { UPF as \% weight + adjusted for TEI and } \\
\text { energy content of UPFs }\end{array}$ & $1.66(1.28,2.16)^{6}$ \\
\hline & IHD/cerebrovascular mortality & HR 1st vs. 4th quartile & $\begin{array}{c}\text { UPF as \% weight + adjusted for TEI and } \\
\text { energy content of UPFs }\end{array}$ & $1.48(1.05,2.09)^{6}$ \\
\hline & Cancer mortality & HR 1st vs. 4th quartile & UPF as \% weight + adjusted for TEI & $1.00(0.80,1.26)^{6}$ \\
\hline & Other cause mortality & HR 1st vs. 4th quartile & UPF as \% weight + adjusted for TEI & $1.36(1.01,1.83)^{6}$ \\
\hline \multirow[t]{2}{*}{ Beslay 2020 [106] } & BMI change $\left(\mathrm{kg} / \mathrm{m}^{2}\right)$ & Beta per $10 \%$ increase in UPF & UPF as \% weight + adjusted for TEI & $0.02(0.01,0.02)^{7}$ \\
\hline & Overweight & HR per $10 \%$ increase in UPF & UPF as \% weight + adjusted for TEI & $1.11(1.08,1.14)^{7}$ \\
\hline Mendonça 2016 [107] & Overweight/obesity & HR 1st vs. 4th quartile & UPF servings/day + adjusted for TEI & $1.27(1.09,1.49)^{8}$ \\
\hline \multirow[t]{2}{*}{ Li $2021[108]$} & Overweight/obesity & OR none vs. $\geq 50 \mathrm{~g} /$ day & Absolute UPF g/day + adjusted for TEI & $1.85(1.58,2.17)^{9}$ \\
\hline & Central obesity & OR none vs. $\geq 50 \mathrm{~g} /$ day & Absolute UPF g/day + adjusted for TEI & $2.04(1.79,2.33)^{9}$ \\
\hline \multirow[t]{3}{*}{ Koniecnzna 2021 [109] } & Total fat mass (z-score) & Beta per $10 \%$ increase in UPF & UPF as \% weight + adjusted for TEI & $0.09(0.06,0.12)^{10}$ \\
\hline & Visceral fat mass (z-score) & Beta per $10 \%$ increase in UPF & UPF as $\%$ weight + adjusted for TEI & $0.09(0.04,0.13)^{10}$ \\
\hline & Android:Gynoid fat ratio (z-score) & Beta per $10 \%$ increase in UPF & UPF as $\%$ weight + adjusted for TEI & $0.04(0.00,0.08) p=0.055^{10}$ \\
\hline Sandoval-Insausti 2020 [110] & Abdominal obesity & OR 1st vs. 3rd tertile & UPF as \% TEI + adjusted for TEI & $2.55(1.04,6.27)^{11}$ \\
\hline \multirow[t]{3}{*}{ Cordova $2021[111]$} & Weight gain $(\mathrm{kg})$ & Beta per 1SD increase in UPF/day & Energy-adjusted UPF & $0.118(0.085,0.151)^{12}$ \\
\hline & Overweight/obesity & RR per 1SD increase in UPF/day & Energy-adjusted UPF & $1.05(1.04,1.06)^{12}$ \\
\hline & Obesity & RR per 1SD increase in UPF/day & Energy-adjusted UPF & $1.05(1.03,1.07)^{12}$ \\
\hline
\end{tabular}


Table 5. Cont.

\begin{tabular}{|c|c|c|c|c|}
\hline Author, Year & Outcome & Method of Analysis & Energy Adjustment & Effect \\
\hline \multirow[t]{3}{*}{ Canhada 2020 [112] } & $\begin{array}{l}\text { Large weight gain }(\geq 90 \text { th percentile: } \\
\qquad 1.68 \mathrm{~kg} / \text { year })\end{array}$ & RR 1st vs. 4th quartile & UPF as \% TEI + adjusted for TEI & $1.27(1.07,1.51)^{13}$ \\
\hline & $\begin{array}{c}\text { Large WC gain ( } \geq 90 \text { th percentile: } \\
>2.42 \mathrm{~cm} / \text { vear })\end{array}$ & RR 1st vs. 4th quartile & UPF as \% TEI + adjusted for TEI & $1.36(1.14,1.61)^{13}$ \\
\hline & Incident obesity & RR 1st vs. 4th quartile & UPF as \% TEI + adjusted for TEI & $1.02(0.85,1.21)^{13}$ \\
\hline \multirow{4}{*}{ Rohatgi 2017 [113] } & Gestational weight gain $(\mathrm{kg})$ & Beta per $1 \%$ increase in UPF intake & UPF as $\%$ TEI + adjusted for TEI & $1.3(0.3,2.4)^{14}$ \\
\hline & Neonate thigh skinfold thickness (mm) & Beta per $1 \%$ increase in UPF intake & UPF as $\%$ TEI + adjusted for TEI & $0.20(0.005,0.40)^{14}$ \\
\hline & $\begin{array}{l}\text { Neonate subscapular skinfold thickness } \\
(\mathrm{mm})\end{array}$ & Beta per $1 \%$ increase in UPF intake & UPF as \% TEI + adjusted for TEI & $0.10(0.02,0.30)^{14}$ \\
\hline & Neonate body fat percentage (\%) & Beta per $1 \%$ increase in UPF intake & UPF as \% TEI + adjusted for TEI & $0.60(0.04,1.20)^{14}$ \\
\hline \multirow[t]{2}{*}{ Gomes 2021 [93] } & $\begin{array}{l}\text { Gestational weight gain 3rd } \\
\text { trimester }(\mathrm{kg})\end{array}$ & $\begin{array}{l}\text { Beta per } 1 \% \text { increase in UPF intake during } \\
\text { 3rd trimester }\end{array}$ & UPF as \% TEI & $4.17(0.55,7.79)^{15}$ \\
\hline & $\begin{array}{l}\text { Gestational weight gain 2nd } \\
\text { trimester }(\mathrm{kg})\end{array}$ & $\begin{array}{l}\text { Beta per 1\% increase in UPF intake in } \\
\text { 2nd trimester }\end{array}$ & UPF as \% TEI & $-1.50(-5.08,2.08)^{15}$ \\
\hline \multirow[t]{3}{*}{ Leone 2021 [114] } & Gestational diabetes pooled & OR 1st vs. 3rd tertile & Energy-adjusted UPF + adjusted for TEI & $1.10(0.74,1.64)^{16}$ \\
\hline & Gestational diabetes $<30$ & OR 1st vs. 3rd tertile & Energy-adjusted UPF + adjusted for TEI & $0.89(0.54,1.46)^{16}$ \\
\hline & Gestational diabetes $\geq 30$ & OR 1st vs. 3rd tertile & Energy-adjusted UPF + adjusted for TEI & $2.05(1.03,4.07)^{16}$ \\
\hline \multirow[t]{8}{*}{ Chang 2021 [115] } & BMI $\left(\mathrm{kg} / \mathrm{m}^{2}\right) /$ year & Beta 1st vs. 5th quintile & UPF as $\%$ weight + adjusted for child's TEI & $0.06(0.04,0.08)^{17}$ \\
\hline & Lean mass index $\left(\mathrm{kg} / \mathrm{m}^{2}\right) /$ year & Beta 1st vs. 5th quintile & UPF as $\%$ weight + adjusted for child's TEI & $0.004(-0.007,0.01)^{17}$ \\
\hline & Body fat percentage $(\%) /$ year & Beta 1st vs. 5th quintile & UPF as $\%$ weight + adjusted for child's TEI & $0.004(-0.05,0.06)^{17}$ \\
\hline & Weight $(\mathrm{kg} /$ year $)$ & Beta 1st vs. 5th quintile & UPF as $\%$ weight + adjusted for child's TEI & $0.20(0.11,0.28)^{17}$ \\
\hline & Waist circumference (cm/year) & Beta 1st vs. 5th quintile & UPF as $\%$ weight + adjusted for child's TEI & $0.17(0.11,0.22)^{17}$ \\
\hline & BMI z-score & Beta 1st vs. 5th quintile & UPF as $\%$ weight + adjusted for child's TEI & $0.01(0.003,0.01)^{17}$ \\
\hline & Fat mass (kg/year) & Beta 1st vs. 5th quintile & UPF as $\%$ weight + adjusted for child's TEI & $0.15(0.08,0.21)^{17}$ \\
\hline & Lean mass $(\mathrm{kg} /$ year $)$ & Beta 1st vs. 5th quintile & UPF as $\%$ weight + adjusted for child's TEI & $-0.04(-0.11,0.02)^{17}$ \\
\hline
\end{tabular}


Table 5. Cont.

\begin{tabular}{|c|c|c|c|c|}
\hline Author, Year & Outcome & Method of Analysis & Energy Adjustment & Effect \\
\hline Costa 2021 [116] & Fat mass index $\left(\mathrm{kg} / \mathrm{m}^{2}\right)$ & Beta/100 g increase in UPF intake & $\begin{array}{l}\text { Absolute UPF g/day + adjusted for energy } \\
\text { intake/expenditure ratio + TEI }\end{array}$ & $0.05(0.04,0.06)^{18}$ \\
\hline \multirow[t]{10}{*}{ Vedovato 2021 [99] } & BMI z-score age 10 & $\begin{array}{c}\text { Beta per } 1 \mathrm{kcal} / 100 \mathrm{kcal} / \mathrm{d} \text { increase in energy } \\
\text { from UPF at age } 4\end{array}$ & UPF as $\%$ TEI at age 4 & $0.028(0.006,0.051)^{19}$ \\
\hline & BMI z-score age 10 & $\begin{array}{c}\text { Beta per } 1 \mathrm{kcal} / 100 \mathrm{kcal} / \mathrm{d} \text { increase in energy } \\
\text { from UPF at age } 7\end{array}$ & UPF as $\%$ TEI at age 7 & $0.014(-0.007,0.036)^{19}$ \\
\hline & Enjoyment of food at age 7 & $\begin{array}{l}\text { Beta per } 1 \mathrm{kcal} / 100 \mathrm{kcal} / \mathrm{d} \text { increase in energy } \\
\text { from UPF at age } 4\end{array}$ & UPF as $\%$ TEI at age 4 & $-0.002(-0.021,0.016)^{19}$ \\
\hline & Food responsiveness at age 7 & $\begin{array}{l}\text { Beta per } 1 \mathrm{kcal} / 100 \mathrm{kcal} / \mathrm{d} \text { increase in energy } \\
\text { from UPF at age } 4\end{array}$ & UPF as $\%$ TEI at age 4 & $0.017(-0.001,0.035)^{19}$ \\
\hline & Emotional overeating at age 7 & $\begin{array}{c}\text { Beta per } 1 \mathrm{kcal} / 100 \mathrm{kcal} / \mathrm{d} \text { increase in energy } \\
\text { from UPF at age } 4\end{array}$ & UPF as $\%$ TEI at age 4 & $0.010(-0.006,0.026)^{19}$ \\
\hline & Emotional undereating at age 7 & $\begin{array}{l}\text { Beta per } 1 \mathrm{kcal} / 100 \mathrm{kcal} / \mathrm{d} \text { increase in energy } \\
\text { from UPF at age } 4\end{array}$ & UPF as $\%$ TEI at age 4 & $0.007(-0.012,0.027)^{19}$ \\
\hline & Satiety Responsiveness at age 7 & $\begin{array}{l}\text { Beta per } 1 \mathrm{kcal} / 100 \mathrm{kcal} / \mathrm{d} \text { increase in energy } \\
\text { from UPF at age } 4\end{array}$ & UPF as $\%$ TEI at age 4 & $0.013(-0.004,0.029)^{19}$ \\
\hline & Slowness in eating at age 7 & $\begin{array}{l}\text { Beta per } 1 \mathrm{kcal} / 100 \mathrm{kcal} / \mathrm{d} \text { increase in energy } \\
\text { from UPF at age } 4\end{array}$ & UPF as $\%$ TEI at age 4 & $-0.015(-0.035,0.006)^{19}$ \\
\hline & Food Fussiness at age 7 & $\begin{array}{l}\text { Beta per } 1 \mathrm{kcal} / 100 \mathrm{kcal} / \mathrm{d} \text { increase in energy } \\
\text { from UPF at age } 4\end{array}$ & UPF as $\%$ TEI at age 4 & $0.026(0.007,0.045)^{19}$ \\
\hline & Desire to Drink at age 7 & $\begin{array}{l}\text { Beta per } 1 \mathrm{kcal} / 100 \mathrm{kcal} / \mathrm{d} \text { increase in energy } \\
\text { from UPF at age } 4\end{array}$ & UPF as $\%$ TEI at age 4 & $0.018(-0.003,0.039)^{19}$ \\
\hline \multirow[t]{7}{*}{ Costa 2019 [98] } & $\triangle \mathrm{BMI}$ age 4 to 8 & Beta per $10 \%$ increase in UPF intake & UPF as $\%$ TEI at age 4 & $0.00(-0.02,0.01)^{20}$ \\
\hline & $\triangle W C$ age 4 to 8 & Beta per $10 \%$ increase in UPF intake & UPF as $\%$ TEI at age 4 & $0.07(0.01,0.13)^{20}$ \\
\hline & $\triangle$ WHR age 4 to 8 & Beta per $10 \%$ increase in UPF intake & UPF as $\%$ TEI at age 4 & $0.00(0.00,0.00)^{20}$ \\
\hline & $\triangle$ Sum skinfolds age 4 to 8 & Beta per $10 \%$ increase in UPF intake & UPF as $\%$ TEI at age 4 & $0.05(-0.04,0.15)^{20}$ \\
\hline & Glucose $(\mathrm{mmol} / \mathrm{L})$ & Beta per $10 \%$ increase in UPF intake & UPF as $\%$ TEI at age 4 & $0.00(-0.01,0.00)^{20}$ \\
\hline & Insulin (uU/mL) & Beta per $10 \%$ increase in UPF intake & UPF as $\%$ TEI at age 4 & $0.00(-0.00,0.01)^{20}$ \\
\hline & HOMA-IR & Beta per $10 \%$ increase in UPF intake & UPF as $\%$ TEI at age 4 & $0.00(-0.01,0.01)^{20}$ \\
\hline \multirow[t]{3}{*}{ Srour 2019 [117] } & All CVD & HR per $10 \%$ increase in UPF & UPF as $\%$ weight + adjusted for TEI & $1.12(1.05,1.20)^{21}$ \\
\hline & Coronary heart disease & HR per $10 \%$ increase in UPF & UPF as \% weight + adjusted for TEI & $1.13(1.02,1.24)^{21}$ \\
\hline & Cerebrovascular disease & HR per $10 \%$ increase in UPF & UPF as $\%$ weight + adjusted for TEI & $1.11(1.01,1.21)^{21}$ \\
\hline Du $2021[86]$ & Incident CAD & HR 1st vs. 4th quartile & Energy-adjusted UPF + adjusted for TEI & $1.21(1.06,1.37)^{22}$ \\
\hline
\end{tabular}


Table 5. Cont.

\begin{tabular}{|c|c|c|c|c|}
\hline Author, Year & Outcome & Method of Analysis & Energy Adjustment & Effect \\
\hline \multirow[t]{4}{*}{ Juul 2021 [118] } & Overall CVD & HR per serving UPF/day & Energy-adjusted UPF + adjusted for TEI & $1.05(1.02,1.08)^{23}$ \\
\hline & CVD mortality & HR per serving UPF/day & Energy-adjusted UPF + adjusted for TEI & $1.09(1.02,1.16)^{23}$ \\
\hline & Incident hard CVD & HR per serving UPF/day & Energy-adjusted UPF + adjusted for TEI & $1.07(1.03,1.12)^{23}$ \\
\hline & Hard coronary heart disease & HR per serving UPF/day & Energy-adjusted UPF + adjusted for TEI & $1.10(1.04,1.15)^{23}$ \\
\hline \multirow[t]{3}{*}{ Zhong 2021 [119] } & CVD mortality & HR 1st vs. 5th quartile & Energy-adjusted UPF + adjusted for TEI & $1.50(1.36,1.64)^{24}$ \\
\hline & Heart disease mortality & HR 1st vs. 5th quartile & Energy-adjusted UPF + adjusted for TEI & $1.68(1.50,1.87)^{24}$ \\
\hline & Cerebrovascular disease mortality & HR 1st vs. 5th quartile & Energy-adjusted UPF + adjusted for TEI & $0.94(0.76,1.17)^{24}$ \\
\hline \multirow[t]{3}{*}{ Scaranni 2021 [120] } & Incident hypertension & OR 1st vs. 3rd tertile & UPF as $\%$ TEI + adjusted for TEI & $1.23(1.06,1.44)^{25}$ \\
\hline & Change in SBP & Beta 1st vs. 3rd tertile & UPF as $\%$ TEI + adjusted for TEI & $-0.54(-1.23,0.15)^{25}$ \\
\hline & Change in DBP & Beta 1st vs. 3rd tertile & UPF as $\%$ TEI + adjusted for TEI & $0.08(-0.39,0.56)^{25}$ \\
\hline Mendonça 2017 [122] & Hypertension & HR 1st vs. 3rd tertile & Energy-adjusted UPF + adjusted for TEI & $1.21(1.06,1.37)^{26}$ \\
\hline Rezende-Alves 2021 [148] & Hypertension & RR 1st vs. 5th quartile & UPF as \% TEI & $1.35(1.01,1.82)^{27}$ \\
\hline \multirow[t]{3}{*}{ Monge 2021 [121] } & Incident hypertension & $\leq 20 \%$ vs. $>45 \%$ of energy from any UPF & UPF as $\%$ TEI + adjusted for TEI & $0.98(0.84,1.14)^{28}$ \\
\hline & Incident hypertension & $\leq 20 \%$ vs. $>45 \%$ of energy from liquid UPF & UPF as \% TEI + adjusted for TEI & $1.34(1.10,1.65)^{28}$ \\
\hline & Incident hypertension & $\leq 20 \%$ vs. $>45 \%$ of energy from solid UPF & UPF as \% TEI + adjusted for TEI & $0.91(0.82,1.01)^{28}$ \\
\hline Llavero-Valero 2021 [123] & $\mathrm{T} 2 \mathrm{DM}$ & HR 1st vs. 3rd tertile & Energy-adjusted UPF + adjusted for TEI & $1.52(1.05,2.22)^{29}$ \\
\hline Srour 2020 [124] & T2DM & HR per $10 \%$ increase in UPF & UPF as $\%$ weight + adjusted for TEI & $1.15(1.06,1.25)^{30}$ \\
\hline Zhang 2021 [125] & NAFLD & HR 1st vs. 4th quartile & UPF g/1000kcal + adjusted for TEI & $1.19(1.08,1.31)^{32}$ \\
\hline \multirow[t]{4}{*}{ Fiolet 2018 [126] } & All cancers & HR per $10 \%$ increase in UPF & $\begin{array}{c}\text { UPF as \% TEI + adjusted for TEI (exc. } \\
\text { Alcohol) }\end{array}$ & $1.12(1.06,1.18)^{33}$ \\
\hline & Breast cancer & HR per $10 \%$ increase in UPF & $\begin{array}{c}\text { UPF as \% TEI + adjusted for TEI (exc. } \\
\text { Alcohol) }\end{array}$ & $1.11(1.02,1.22)^{33}$ \\
\hline & Prostate cancer & HR per $10 \%$ increase in UPF & $\begin{array}{l}\text { UPF as } \% \text { TEI + adjusted for TEI (exc. } \\
\text { Alcohol) }\end{array}$ & $0.98(0.83,1.16)^{33}$ \\
\hline & Colorectal cancer & HR per $10 \%$ increase in UPF & $\begin{array}{c}\text { UPF as } \% \text { TEI }+ \text { adjusted for TEI (exc. } \\
\text { Alcohol) }\end{array}$ & $1.13(0.92,1.38)^{33}$ \\
\hline Vasseur 2021 [127] & IBD & RR 1st vs. 3rd tertile & UPF as \% weight + adjusted for TEI & $1.44(0.70,2.94)^{34}$ \\
\hline \multirow[t]{3}{*}{ Narula 2021 [128] } & IBD & $\mathrm{HR}<1$ vs. $\geq 5$ servings UPF/day & UPF servings/day + adjusted for TEI & $1.82(1.22,2.72)^{35}$ \\
\hline & Crohn's disease & HR $<1$ vs. $\geq 5$ servings UPF/day & UPF servings/day + adjusted for TEI & $4.50(1.67,12.13)^{35}$ \\
\hline & Ulcerative Colitis & HR $<1$ vs. $\geq 5$ servings UPF/day & UPF servings/day + adjusted for TEI & $1.46(0.93,2.28)^{35}$ \\
\hline
\end{tabular}


Table 5. Cont.

\begin{tabular}{|c|c|c|c|c|}
\hline Author, Year & Outcome & Method of Analysis & Energy Adjustment & Effect \\
\hline \multirow[t]{4}{*}{ Schnabel 2018 [129] } & Irritable bowel syndrome & OR 1st vs. 4th quartile & UPF as \% weight + adjusted for TEI & $1.24(1.12,1.38)^{36}$ \\
\hline & Functional Constipation & OR 1st vs. 4th quartile & UPF as $\%$ weight + adjusted for TEI & $1.00(0.87,1.15)^{36}$ \\
\hline & Functional diarrhoea & OR 1st vs. 4th quartile & UPF as $\%$ weight + adjusted for TEI & $0.94(0.71,1.26)^{36}$ \\
\hline & Functional dyspepsia & OR 1st vs. 4th quartile & UPF as $\%$ weight + adjusted for TEI & $1.26(1.07,1.48)^{36}$ \\
\hline \multirow[t]{2}{*}{ Lo 2021 [130] } & Crohn's disease & HR 1st vs. 4th quartile & UPF as \% TEI + adjusted for TEI & $1.70(1.23,2.35)^{37}$ \\
\hline & Ulcerative Colitis & HR 1st vs. 4th quartile & UPF as $\%$ TEI + adjusted for TEI & $1.20(0.91,1.58)^{37}$ \\
\hline Adjibade 2019 [131] & Depressive symptoms & per $10 \%$ increase in UPF & UPF as $\%$ weight + adjusted for TEI & $1.21(1.15,1.27)^{38}$ \\
\hline Gómez-Donoso 2020 [132] & Incident depression & HR 1st vs. 4th quartile & Energy-adjusted UPF + adjusted for TEI & $1.33(1.07,1.64)^{39}$ \\
\hline Rey-Garcia 2021 [133] & Renal function & OR 1st vs. 3rd tertile & UPF as \% TEI + adjusted for TEI & $1.75(1.16,2.64)^{40}$ \\
\hline Zhang 2021 [134] & Hyperuricemia & HR 1st vs. 4th quartile & UPF servings/day + adjusted for TEI & $1.17(1.06,1.30)^{41}$ \\
\hline \multirow{4}{*}{ Leffa 2020 [135] } & Total cholesterol at age 6 & Beta per $10 \%$ increase in UPF intake at age 3 & UPF as \% TEI + adjusted for TEI & $0.07(0.00,0.14) p=0.046^{42}$ \\
\hline & LDL-cholesterol at age 6 & Beta per $10 \%$ increase in UPF intake at age 3 & UPF as \% TEI + adjusted for TEI & $0.03(-0.03,0.09)^{42}$ \\
\hline & HDL-cholesterol at age 6 & Beta per $10 \%$ increase in UPF intake at age 3 & UPF as $\%$ TEI + adjusted for TEI & $0.01(-0.02,0.05)^{42}$ \\
\hline & TAG at age 6 & Beta per $10 \%$ increase in UPF intake at age 3 & UPF as $\%$ TEI + adjusted for TEI & $0.04(0.01,0.07) p=0.024^{42}$ \\
\hline \multirow[t]{4}{*}{ Rauber 2015 [95] } & $\Delta$ Total cholesterol from $3-4$ to $7-8$ & Beta per $1 \%$ increase in energy from UPF & UPF as $\%$ TEI + adjusted for TEI at age $7-8$ & $0.430(0.008,0.853)^{43}$ \\
\hline & $\Delta$ LDL cholesterol from 3-4 to 7-8 & Beta per $1 \%$ increase in energy from UPF & UPF as $\%$ TEI + adjusted for TEI at age $7-8$ & $0.369(0.005,0.733)^{43}$ \\
\hline & $\Delta \mathrm{nHDL}$ cholesterol from $3-4$ to $7-8$ & Beta per $1 \%$ increase in energy from UPF & UPF as $\%$ TEI + adjusted for TEI at age $7-8$ & $0.319(-0.059,0.697)^{43}$ \\
\hline & $\Delta \mathrm{HDL}$ cholesterol from $3-4$ to $7-8$ & Beta per $1 \%$ increase in energy from UPF & UPF as $\%$ TEI + adjusted for TEI at age 7-8 & $0.125(-0.026,0.277)^{43}$ \\
\hline \multirow[t]{6}{*}{ Donat-Vargas 2021 [136] } & $\begin{array}{c}\text { Incident hypertriglyceridemia ( } \geq 150 \\
\mathrm{mg} / \mathrm{dL})\end{array}$ & OR 1st vs. 3rd tertile & UPF as \% TEI + adjusted for TEI & $2.21(1.09,4.49)^{44}$ \\
\hline & $\begin{array}{l}\text { Low HDL-cholesterol }(<40 \text { in men or }<50 \\
\mathrm{mg} / \mathrm{dL} \text { in women })\end{array}$ & OR 1st vs. 3rd tertile & UPF as $\%$ TEI + adjusted for TEI & $2.04(1.18,3.53)^{44}$ \\
\hline & High LDL-cholesterol (>129 mg/dL) & OR 1st vs. 3rd tertile & UPF as $\%$ TEI + adjusted for TEI & $1.13(0.52,2.46)^{44}$ \\
\hline & $\Delta$ triglycerides $(\mathrm{mg} / \mathrm{dL})$ & Beta 1st vs. 3rd tertile & UPF as $\%$ TEI + adjusted for TEI & $6.23(1.26,11.21)^{44}$ \\
\hline & $\Delta$ HDL cholesterol $(\mathrm{mg} / \mathrm{dL})$ & Beta 1st vs. 3rd tertile & UPF as $\%$ TEI + adjusted for TEI & $0.02(-1.45,1.49)^{44}$ \\
\hline & $\Delta$ LDL cholesterol (mg/dL) & Beta 1st vs. 3rd tertile & UPF as $\%$ TEI + adjusted for TEI & $-3.43(-8.60,1.74)^{44}$ \\
\hline
\end{tabular}


Table 5. Cont.

\begin{tabular}{|c|c|c|c|c|}
\hline Author, Year & Outcome & Method of Analysis & Energy Adjustment & Effect \\
\hline \multirow{4}{*}{ Machado Azeredo 2020 [101] } & Wheeze at age 11 & OR 1st vs. 5th quintile of UPF at age 6 & UPF as $\%$ TEI + adjusted for TEI and TEI:EEI & $0.78(0.51,1.19)^{45}$ \\
\hline & Asthma at age 11 & OR 1st vs. 5th quintile of UPF at age 6 & UPF as \% TEI + adjusted for TEI and TEI:EEI & $0.83(0.59,1.17)^{45}$ \\
\hline & Mild/moderate asthma at age 11 & OR 1st vs. 5th quintile of UPF at age 6 & UPF as $\%$ TEI + adjusted for TEI and TEI:EEI & $0.63(0.34,1.17)^{45}$ \\
\hline & Severe Asthma at age 11 & OR 1st vs. 5th quintile of UPF at age 6 & UPF as \% TEI + adjusted for TEI and TEI:EEI & $0.94(0.54,1.65)^{45}$ \\
\hline \multirow[t]{3}{*}{ Borge 2021 [137] } & ADHD diagnosis at 8 years & RR per 1 SD increase in UPF & UPF as \% TEI & $1.07(0.99,1.18)^{46}$ \\
\hline & ADHD symptoms (absolute) at 8 years & Beta per 1 SD increase in UPF & UPF as \% TEI & $0.25(0.13,0.38)^{46, *}$ \\
\hline & ADHD symptoms (relative) at 8 years & Beta per 1 SD increase in UPF & $\mathrm{UPF}$ as $\% \mathrm{TEI}$ & $3.0(1.5,4.5)^{46, *}$ \\
\hline Zhang 2021 [138] & Change in grip strength $(\mathrm{kg} /$ year $)$ & Beta per $10 \%$ increase in UPF & UPF as $\%$ weight + adjusted for TEI & $-0.3207(-0.5281,-0.1133)^{47}$ \\
\hline
\end{tabular}

Energy-adjusted UPF via the residual method. TEI, total energy intake; TEI:EEI, energy intake:expenditure ratio; OR, odds ratio, HR, hazard ratio; RR, relative risk; ADHD, attention deficit hyperactivity disorder; CVD, cardiovascular disease; IHD, ischemic heart disease; HOMA-IR, Homeostatic Model Assessment for Insulin Resistance; BMI, body mass index T2DM, type 2 diabetes mellitus; IBD, inflammatory bowel disease; NAFLD, non-alcoholic fatty liver disease; UPF, ultra-processed food; SBP, systolic blood pressure; DBP, diastolic blood pressure; LDL, low-density lipoprotein; HDL, high-density lipoprotein; nHDL, non-high-density lipoprotein; TAG, triacylglycerol; WC, waist circumference; WHR, waist-to-hip ratio. ${ }^{1}$ Adjusted for sex, age, income level, education level, marital status, residence, BMI, physical activity level, smoking status, energy intake, alcohol intake, season of food records, first-degree family history of cancer or cardiovascular diseases and number of food records. ${ }^{2}$ Adjusted for age, sex, marital status, physical activity, smoking status, snacking, special diet at baseline, BMI, total energy intake, alcohol consumption, family history of CVD, diabetes or hypertension at baseline, self-reported hypercholesterolaemia, baseline CVD, cancer or depression, education level and lifelong smoking stratified by recruitment period, deciles of age, sedentary index (sum of hours each day spent watching television, using a computer and driving) and television viewing. ${ }^{3}$ Adjusted for age, sex, education level, living alone, smoking status, former drinker, physical activity, time watching television, time devoted to other sedentary activities, number of medications per day and specific chronic conditions diagnosed by a physician (chronic respiratory disease, coronary heart disease, stroke, heart intake. ${ }^{5}$ Adjusted for age, sex, BMI, physical activity, alcohol intake, smoking status and total energy intake. ${ }^{6}$ Adjusted for sex, age, energy intake, educational level, housing tenure, smoking, BMI, leisure-time physical activity, history of cancer, CVD, diabetes, hypertension and hyperlipidaemia and residence. ${ }^{7}$ Adjusted for age, sex, marital status, educational level, physical activity, smoking status, alcohol consumption, energy intake and number of dietary records (overweight and obesity outcomes further adjusted for baseline BMI). ${ }^{8}$ Adjusted for age, sex, marital status, educational status, physical activity, energy intake, television watching, siesta sleep, smoking status, snacking between meals, following a special diet at baseline, baseline BMI and consumption of fruit and vegetables. ${ }^{9}$ Adjusted for age, sex and energy intake. ${ }^{10}$ Adjusted for age, sex, study arm, follow-up time, educational level, marital status, smoking habits, type 2 diabetes prevalence, height and repeated measures of total energy intake, physical activity and sedentary behaviour. ${ }^{11}$ Adjusted for age, sex, educational level, marital status, smoking, ex-drinker status, physical activity in the household and at leisure time, number of medications consumed per day, number of chronic diseases diagnosed by a doctor (chronic obstructive pulmonary disease/asthma, coronary heart disease, stroke, heart failure, osteoarthritis or depression) and total energy intake, Mediterranean dietary pattern, fibre and very long chain omega-3 fatty acid intake. ${ }^{12}$ Adjusted for age, sex, baseline BMI, educational level, physical activity, baseline alcohol intake, status and plausibility of dietary energy reporting and for the modified relative Mediterranean diet score. Overweig country/centre, follow-up time in years and smoking status at follow-up (instead of baseline smoking status). ${ }^{13}$ Adjusted for age, sex, colour/race, centre, income, school achievement, smoking, physical activity and energy intake. Additionally for incident overweight/obesity and weight gain: baseline BMI. Additionally for waist gain: waist circumference at baseline. ${ }^{14}$ Adjusted for maternal age, race, socioeconomic status, weight status, average daily energy intake, time spent in moderate physical activity and fat intake. ${ }^{15}$ Adjusted for cohort and potential confounding variables, with $p<0 \cdot 25$. ${ }^{16}$ Adjusted for age, BMI, education, smoking status, physical activity, family history of diabetes, recruitment year, time between recruitment and the first pregnancy or gestational diabetes, number of pregnancies during follow-up, parity, multiple pregnancies, time spent watching TV, hypertension, following a nutritional therapy, and energy intake. ${ }^{17}$ Adjusted for age, baseline UPF, age*baseline UPF interaction term, child sex, race, birth weight, physical activity, quintiles of Index of Multiple Deprivation, the mother's prepregnancy BMI, marital status, highest educational attainment, socioeconomic status and the child's baseline total energy intake. ${ }^{18}$ Adjusted for skin colour, maternal age and schooling, birthweight and sex, screen time, total energy intake and energy intake/expenditure ratio. ${ }^{19}$ Adjusted for maternal age, maternal education and BM before pregnancy, exclusive breast-feeding for the first 6 months, child physical exercise and daily screen time. For appetitive behaviours, additionally parental concerns, and for BMI, additionally child BMI z-score at 4 years old. ${ }^{20}$ Adjusted for sex, group status in the early phase (intervention and control), pre-pregnancy BMI, birth weight, breastfeeding, family 
income, maternal schooling and total screen duration. ${ }^{21}$ Adjusted for age, sex, energy intake, number of 24-h dietary records, smoking status, educational level, physical activity, BMI, alcohol intake, and family history of CVD. ${ }^{22}$ Adjusted for age, sex, race, centre and total energy intake. ${ }^{23}$ Adjusted for age, sex, education, smoking status, alcohol intake, total energy intake and physical activity. ${ }^{24}$ Adjusted for age, sex, race, educational level, marital status, study centre, aspirin use, history of hypertension or diabetes, smoking status, alcohol consumption, BMI, physical activity and energy intake. ${ }^{25}$ Adjusted for age, sex, colour or race, education, time since baseline, SBP/DBP/hypertension, physical activity, smoking, alcohol consumption, sodium intake and total energy intake. ${ }^{26}$ Adjusted for age, sex, physical activity, hours of TV watching, baseline BMI, smoking status, use of analgesics, following a special diet at baseline, family history of hypertension, hypercholesterolemia, alcohol consumption, total energy intake, olive oil intake and consumption of fruits and vegetables. ${ }^{27}$ Adjusted for age, marital status, skin colour, per capita income, physical activity, smoking, obesity, family history of hypertension and previous diagnosis of T2DM, hypercholesterolaemia and hypertriglyceridaemia. ${ }^{28}$ Adjusted for age, indigenous, internet access, insurance, family history of hypertension, menopausal status, smoking status, physical activity, total energy intake and multivitamin intake. ${ }^{29}$ Adjusted for age, sex, BMI, educational status, family history of diabetes, smoking status, snacking between meals, active and sedentary lifestyle score, following a special diet at baseline and total energy intake. ${ }^{30}$ Adjusted for age, sex, educational level, baseline BMI, physical activity, smoking status, alcohol intake, number of 24-h dietary records, total energy intake, Food Standards Agency nutrient profiling system dietary index score, and family history of T2DM. ${ }^{31}$ Adjusted for age, sex, ethnicity, family history of T2DM, Index of Multiple Deprivation, physical activity level, current smoking status and total energy intake. ${ }^{32}$ Adjusted for age, sex, BMI healthy diet score, total energy intake, smoking status, alcohol drinking status, educational level, occupation, monthly household income, physical activity, family history of disease (including cardiovascular disease, hypertension, hyperlipidaemia and diabetes) and depressive symptoms. ${ }^{33}$ Adjusted for age, sex, total energy intake without alcohol, number of 24 -h dietary records, smoking status, educational level, physical activity, height, BMI, alcohol intake, family history of cancers (and for breast cancer outcome, additionally adjusted for menopausal status, hormonal treatment for menopause, oral contraception and number of children). ${ }^{34}$ Adjusted for age, sex, income level, education level, marital status, residence, BMI, physical activity, smoking status, hormonal contraception, number of 24-h dietary records, healthy dietary pattern and total energy intake. ${ }^{35}$ Adjusted for age, sex, geographical region, education, alcohol intake, smoking status, BMI, total energy intake, and location. ${ }^{36}$ Adjusted for age, sex, income level, education level, marital status, residence, BMI, physical activity, smoking status, total energy intake, season of food records and time between food record and functional gastrointestinal disorders questionnaire. ${ }^{37}$ Adjusted for age, cohort, calendar year, AHEI-2010, race, family history of IBD, smoking, BMI, physical activity, total energy intake, regular NSAIDs use, oral contraceptives use and menopausal hormone therapy. ${ }^{38}$ Adjusted for age, sex, BMI, marital status, educational level, occupational categories, household income per consumption unit, residential area, number of 24-h dietary records, inclusion month, total energy intake without alcohol, alcohol intake, smoking status and physical activity. ${ }^{39}$ Adjusted for age, sex, year of entrance to the cohort, Mediterranean diet, baseline BMI, total energy intake, physical activity, smoking status, marital status, living alone, employment status, working hours per week, health-related career, years of education and baseline self-perception of competitiveness, anxiety and dependence levels. ${ }^{40}$ Adjusted for age, sex and total energy intake. ${ }^{41}$ Adjusted for age, sex, BMI, smoking status, alcohol consumption status, education levels, employment status, household income, physical activity, depression symptoms, family history of disease (including cardiovascular disease, hypertension hyperlipidaemia and diabetes), hypertension, hyperlipidaemia, diabetes, metabolic syndrome, total energy intake and dietary patterns (sweet, animal and healthy patterns). ${ }^{42}$ Adjusted for sex, group status in the early phase (intervention and control), family income, pre-pregnancy BMI, childbirth weight, BMI z-scores at 3 years, total energy and total fat intake at 3 years. ${ }^{43}$ Adjusted for sex, group, birth weight, family income, maternal schooling, BMI-for-age z-scores and total energy intake at $7-8$ years. ${ }^{44}$ Adjusted for age, sex, fibre intake, total energy intake, educational level, marital status, smoking status, BMI, physical activity, alcohol consumption, number of medications and number of chronic conditions. ${ }^{45}$ Adjusted for TEI and TEI:EEI. ${ }^{46}$ Adjusted for child diet quality score using Diet Quality Index at 3 years, maternal pre-pregnancy BMI, maternal education, smoking and alcohol intake during pregnancy, maternal symptoms of depression and ADHD, maternal age, parity, child sex and child birth quarter. ${ }^{77}$ Adjusted for baseline age, sex, BMI, smoking status, alcohol drinking status, education level, employment, monthly household in symptoms, hypertension, hyperlipidaemia, diabetes, total energy intake, healthy diet score, dietary supplement use, total protein intake and milk intake. * $95 \%$ credible intervals. 


\section{Discussion}

This review provides novel insights into the relative impact of nutrient content and dietary patterns vs. ultra-processing on obesity and adverse health-related outcomes. The analyses reported here from prospective cohort studies have been largely unexplored to date. Consistent across many studies, adjustment for fat, sugar and sodium intake, or adjustment for adherence to a range of healthy or unhealthy dietary patterns has a minimal impact on the adverse associations between UPF intake and a diverse range of healthrelated outcomes. These findings strongly point towards aspects of ultra-processing as being important factors that impact health, and question the ability to conclude that the adverse outcomes from UPFs can be solely attributed to their nutritional quality.

A meta-analysis of nationally representative samples demonstrates that diets high in UPF tend to contain greater intakes of energy, free sugars, total and saturated fat, and lower intakes of fibre, protein and some micronutrients [30]. The NOVA classification therefore captures important aspects of nutrient quality, despite this not being a core aspect of the UPF definition [28]. It is unsurprising therefore, that the detrimental associations between UPF intake and obesity, CVD and all-cause mortality have been largely attributed to the poor nutritional quality of high UPF diets [71]. If this were the case, then adjustment for aspects of dietary quality should explain the associations between UPFs and poor health outcomes, or at least, explain a significant proportion of the association. However, the majority of the models from prospective studies retain a significantly increased risk of poor health from UPF intake, and are also largely unaltered in magnitude, following dietary adjustment. The findings from this review are in alignment with the results from a metabolic ward cross-over study, the only randomised controlled trial comparing diets of differing levels processing [49]. Participants consumed ad libitum, minimally processed or ultra-processed diets, matched for energy and nutrient content, for two weeks each. The ultra-processed diet resulted in greater energy intake $(+508 \pm 106 \mathrm{kcal} /$ day $)$, leading to weight gain $(+0.9 \pm 0.3 \mathrm{~kg})$. In contrast, the minimally processed diet resulted in weight loss $(-0.9 \pm 0.3 \mathrm{~kg})$, despite diets being matched for energy and nutrient content [49].

The Mediterranean diet, considered to be one of the healthiest dietary patterns for reducing CVD risk [151], consists predominantly of whole grains, fruits, vegetables, beans, pulses and legumes, of which, their consumption is inversely associated with UPF intake [30]. Therefore, the impact of UPFs on health could just be that they displace more healthful foods, or that they overlap with pre-established unhealthy dietary patterns. However, adjustment for Mediterranean diet adherence, for the Western dietary pattern or for other dietary pattern indices, did not alter the majority of the significant associations between UPF intake and health-related outcomes, including the increased risk of weight gain or obesity.

High UPF diets are also characterised by the displacement of minimally processed foods, as defined by NOVA [30]. Few studies have performed dietary adjustment for other NOVA food groups. However, in those that have, adjustment for other NOVA food groups not only did not explain, but in fact, increased the risk associated with UPF intake and FMI gain from age 6 to 11 [116], and adjustment for unprocessed or minimally processed food intake did not alter the increased risk of T2DM [124].

Although limited at this stage, these adjustments would suggest that UPF intake has a direct effect on health-related outcomes, rather than simply displacing healthy foods intake. This may indicate the importance of considering the nature and extent of food processing as an important dimension of dietary pattern analysis.

Discussions over the relative importance of nutrient content vs. ultra-processing continue $[24,81]$. However, recent reports have not taken into account the dietary adjustments from prospective studies reported in this review $[24,81,152]$. The aspects of ultra-processing that lead to adverse health outcomes are poorly understood, and the findings from this review highlight the need for research into mechanisms of ultra-processing as being a priority, in order to determine the long-term potential for UPF reformulation, or need for elimination to address the growing obesity pandemic. On a case-by-case basis, choosing 
UPF reformulations over high fat, salt or sugar alternatives can be beneficial to reduce intakes of nutrients to limit, which are known to be associated with poor health [153]. However, given the high prevalence of UPFs within diets [30], if ultra-processing itself directly results in poor health, then scaling up the case-by-case reformulation approach to the whole diet still leaves an ultra-processed dietary pattern that displaces minimally processed foods, and thus will not sufficiently address current health risks. The nutritional quality of food is important, but is not the sole determinant of the healthiness of a diet [10]. The importance of dietary patterns, food groups and foods as a whole, rather than specific individual nutrients, has previously been highlighted $[8,154]$. Indeed, the diversity of chemicals and nutrients consumed in human diets is vast, yet current nutrient profiling methods only consider a fraction of the 26,000 or so biochemicals in food [155].

Current dietary policies vary across nations and health organisations. The public health implications regarding whether UPFs should be reformulated based on nutrient content or removed from the diet are important. The UK government and Cancer Research UK currently adopt a reformulation approach to high fat, salt or sugar foods, and do not consider the nature and extent of processing in their dietary recommendations [156-158]. However, advice to avoid UPFs is becoming increasingly more prevalent. The American Heart Association now recommends limiting UPF intake [12], and the World Health Organisation and UNICEF recognise the importance of UPF consumption for ending childhood obesity $[159,160]$. UPFs are also recognised by the Pan American Health Organisation as important for reducing health risk, as part of their nutrient profiling model [161]. Some national dietary guidelines now encourage limiting UPF intake including Brazil [162], Uruguay [163] and Israel [164]. France is also planning to reduce UPF consumption by $20 \%$ from 2018 to 2021 [165].

This review discusses the results from over 1,000,000 participants across more than 20 different prospective cohorts, covering many countries, demographic profiles and age groups. The studies in this review utilise dietary assessment methods including 24-hour dietary records and food frequency questionnaires, that are not designed specifically for the application of NOVA classification. Similar foods can be classed as ultra-processed (e.g., pre-packaged bread) or processed (e.g., artisanal bread), which may result in the misclassification of foods with the dietary assessment methods used. Furthermore, other important dietary aspects may have not been captured or suitably adjusted for. Most studies have adjusted for fat, sugar and sodium intake or for overall dietary patterns, which are important dietary factors for health, and proposed to be explanatory factors for the associations between UPF intake and health outcomes.

\section{Conclusions}

Experts for and against the NOVA classification have often focussed on nutrient quality as an important explanatory link between UPFs, obesity and adverse health-related outcomes. However, many of the prospective studies published to date have performed analyses adjusting for nutrient content and overall dietary patterns. These adjustments do not explain the association between UPFs, obesity and adverse health-related outcomes, with estimates remaining significant. These findings raise important questions regarding current policy and future research needs, suggesting that the nature and extent of processing is an important dietary dimension, and whether UPF reformulations can sufficiently address the growing transition towards high UPF diets and the associated risk of obesity and poor health.

Supplementary Materials: The following are available online at https:/ /www.mdpi.com/article/ 10.3390/nu14010023/s1, Table S1: Prospective studies adjusting for fat, sodium and carbohydrate intake and dietary pattern, Table S2: Prospective studies adjusting for components of fat, sodium and carbohydrates, Table S3: Prospective studies adjusting for other dietary components.

Author Contributions: S.J.D., writing—-first draft; R.L.B., writing—editing and reviewing, supervision. All authors have read and agreed to the published version of the manuscript. 
Funding: S.J.D. is funded by a Medical Research Council grant (MR/N013867/1). R.L.B. is funded by the National Institute for Health Research, Sir Jules Thorn Charitable Trust and Rosetrees Trust.

Institutional Review Board Statement: Not applicable.

Informed Consent Statement: Not applicable.

Data Availability Statement: Not applicable.

Acknowledgments: The authors would like to thank Chloe Firman for her review of the final draft.

Conflicts of Interest: The authors declare no conflict of interest.

\section{References}

1. WHO. Obesity. Available online: https://www.who.int/westernpacific/health-topics/obesity (accessed on 7 July 2021).

2. Steel, N.; Ford, J.A.; Newton, J.N.; Davis, A.C.J.; Vos, T.; Naghavi, M.; Glenn, S.; Hughes, A.; Dalton, A.M.; Stockton, D.; et al. Changes in Health in the Countries of the UK and 150 English Local Authority Areas 1990-2016: A Systematic Analysis for the Global Burden of Disease Study 2016. Lancet 2018, 392, 1647-1661. [CrossRef]

3. Kolotkin, R.L.; Andersen, J.R. A Systematic Review of Reviews: Exploring the Relationship between Obesity, Weight Loss and Health-Related Quality of Life. Clin. Obes. 2017, 7, 273-289. [CrossRef] [PubMed]

4. Di Angelantonio, E.; Bhupathiraju, S.N.; Wormser, D.; Gao, P.; Kaptoge, S.; De Gonzalez, A.B.; Cairns, B.J.; Huxley, R.; Jackson, C.L.; Joshy, G.; et al. The Global BMI Mortality Collaboration Body-Mass Index and All-Cause Mortality: Individual-Participant-Data Meta-Analysis of 239 Prospective Studies in Four Continents. Lancet 2016, 388, 776-786. [CrossRef]

5. Afshin, A.; Sur, P.J.; Fay, K.A.; Cornaby, L.; Ferrara, G.; Salama, J.S.; Mullany, E.C.; Abate, K.H.; Abbafati, C.; Abebe, Z.; et al. Health Effects of Dietary Risks in 195 Countries, 1990-2017: A Systematic Analysis for the Global Burden of Disease Study 2017. Lancet 2019, 393, 1958-1972. [CrossRef]

6. Stanaway, J.D.; Afshin, A.; Gakidou, E.; Lim, S.S.; Abate, D.; Abate, K.H.; Abbafati, C.; Abbasi, N.; Abbastabar, H.; Abd-Allah, F.; et al. Global, Regional, and National Comparative Risk Assessment of 84 Behavioural, Environmental and Occupational, and Metabolic Risks or Clusters of Risks for 195 Countries and Territories, 1990-2017: A Systematic Analysis for the Global Burden of Disease Study 2017. Lancet 2018, 392, 1923-1994. [CrossRef]

7. Mozaffarian, D.; Rosenberg, I.; Uauy, R. History of Modern Nutrition Science-Implications for Current Research, Dietary Guidelines, and Food Policy. BMJ 2018, 361, k2392. [CrossRef] [PubMed]

8. Mozaffarian, D. Dietary and Policy Priorities for Cardiovascular Disease, Diabetes, and Obesity: A Comprehensive Review. Circulation 2016, 133, 187-225. [CrossRef]

9. Micha, R.; Shulkin, M.L.; Peñalvo, J.L.; Khatibzadeh, S.; Singh, G.M.; Rao, M.; Fahimi, S.; Powles, J.; Mozaffarian, D. Etiologic Effects and Optimal Intakes of Foods and Nutrients for Risk of Cardiovascular Diseases and Diabetes: Systematic Reviews and Meta-Analyses from the Nutrition and Chronic Diseases Expert Group (NutriCoDE). PLoS ONE 2017, 12, e0175149. [CrossRef]

10. Katz, D.L.; Meller, S. Can We Say What Diet Is Best for Health? Annu. Rev. Public Health 2014, 35, 83-103. [CrossRef] [PubMed]

11. English, L.K.; Ard, J.D.; Bailey, R.L.; Bates, M.; Bazzano, L.A.; Boushey, C.J.; Brown, C.; Butera, G.; Callahan, E.H.; de Jesus, J.; et al. Evaluation of Dietary Patterns and All-Cause Mortality: A Systematic Review. JAMA Netw. Open 2021, 4, e2122277. [CrossRef]

12. Lichtenstein, A.H.; Appel, L.J.; Vadiveloo, M.; Hu, F.B.; Kris-Etherton, P.M.; Rebholz, C.M.; Sacks, F.M.; Thorndike, A.N.; Van Horn, L.; Wylie-Rosett, J.; et al. 2021 Dietary Guidance to Improve Cardiovascular Health: A Scientific Statement from the American Heart Association. Circulation 2021, 144, e472-e487. [CrossRef]

13. Schlesinger, S.; Neuenschwander, M.; Schwedhelm, C.; Hoffmann, G.; Bechthold, A.; Boeing, H.; Schwingshackl, L. Food Groups and Risk of Overweight, Obesity, and Weight Gain: A Systematic Review and Dose-Response Meta-Analysis of Prospective Studies. Adv. Nutr. 2019, 10, 205-218. [CrossRef] [PubMed]

14. Schwingshackl, L.; Schwedhelm, C.; Hoffmann, G.; Lampousi, A.-M.; Knüppel, S.; Iqbal, K.; Bechthold, A.; Schlesinger, S.; Boeing, H. Food Groups and Risk of All-Cause Mortality: A Systematic Review and Meta-Analysis of Prospective Studies. Am. J. Clin. Nutr. 2017, 105, 1462-1473. [CrossRef]

15. Tapsell, L.C.; Neale, E.P.; Satija, A.; Hu, F.B. Foods, Nutrients, and Dietary Patterns: Interconnections and Implications for Dietary Guidelines. Adv. Nutr. 2016, 7, 445-454. [CrossRef] [PubMed]

16. Wirfält, E.; Drake, I.; Wallström, P. What Do Review Papers Conclude about Food and Dietary Patterns? Food Nutr. Res. 2013, 57, 20523. [CrossRef]

17. Fabiani, R.; Naldini, G.; Chiavarini, M. Dietary Patterns and Metabolic Syndrome in Adult Subjects: A Systematic Review and Meta-Analysis. Nutrients 2019, 11, 2056. [CrossRef]

18. Srour, B.; Touvier, M. Ultra-Processed Foods and Human Health: What Do We Already Know and What Will Further Research Tell Us? EClinicalMedicine 2021, 32, 100747. [CrossRef]

19. Popkin, B. Ultra-Processed Foods' Impacts on Health. 2030-Food, Agriculture and Rural Development in Latin America and the Caribbean, No. 34. Santiago de Chile. FAO. 2019. Available online: https://www.fao.org/documents/card/en/c/ca7349en/ (accessed on 14 October 2021). 
20. Zobel, E.H.; Hansen, T.W.; Rossing, P.; von Scholten, B.J. Global Changes in Food Supply and the Obesity Epidemic. Curr. Obes. Rep. 2016, 5, 449-455. [CrossRef] [PubMed]

21. Popkin, B.M.; Adair, L.S.; Ng, S.W. The Global Nutrition Transition: The Pandemic of Obesity in Developing Countries. Nutr. Rev. 2012, 70, 3-21. [CrossRef] [PubMed]

22. Ng, M.; Fleming, T.; Robinson, M.; Thomson, B.; Graetz, N.; Margono, C.; Mullany, E.C.; Biryukov, S.; Abbafati, C.; Abera, S.F.; et al. Global, Regional, and National Prevalence of Overweight and Obesity in Children and Adults during 1980-2013: A Systematic Analysis for the Global Burden of Disease Study 2013. Lancet 2014, 384, 766-781. [CrossRef]

23. Mozaffarian, D.; Ludwig, D.S. Dietary Guidelines in the 21st Century-A Time for Food. JAMA 2010, 304, 681-682. [CrossRef] [PubMed]

24. Tobias, D.K.; Hall, K.D. Eliminate or Reformulate Ultra-Processed Foods? Biological Mechanisms Matter. Cell Metab. 2021, 33, 2314-2315. [CrossRef] [PubMed]

25. Crino, M.; Barakat, T.; Trevena, H.; Neal, B. Systematic Review and Comparison of Classification Frameworks Describing the Degree of Food Processing. Nutr. Food Technol. Open Access 2017, 3. [CrossRef]

26. Monteiro, C.A.; Cannon, G.; Moubarac, J.-C.; Levy, R.B.; Louzada, M.L.C.; Jaime, P.C. The UN Decade of Nutrition, the NOVA Food Classification and the Trouble with Ultra-Processing. Public Health Nutr. 2018, 21, 5-17. [CrossRef]

27. Monteiro, C.A.; Cannon, G.; Levy, R.; Moubarac, J.-C.; Jaime, P.; Martins, A.P.; Canella, D.; Louzada, M.; Parra, D. NOVA. The Star Shines Bright. World Nutr. J. 2016, 7, 28-38.

28. Monteiro, C.A.; Cannon, G.; Levy, R.B.; Moubarac, J.-C.; Louzada, M.L.; Rauber, F.; Khandpur, N.; Cediel, G.; Neri, D.; Martinez-Steele, E.; et al. Ultra-Processed Foods: What They Are and How to Identify Them. Public Health Nutr. 2019, $22,936-941$. [CrossRef] [PubMed]

29. Baker, P.; Machado, P.; Santos, T.; Sievert, K.; Backholer, K.; Hadjikakou, M.; Russell, C.; Huse, O.; Bell, C.; Scrinis, G.; et al. Ultra-Processed Foods and the Nutrition Transition: Global, Regional and National Trends, Food Systems Transformations and Political Economy Drivers. Obes. Rev. 2020, 21, e13126. [CrossRef]

30. Martini, D.; Godos, J.; Bonaccio, M.; Vitaglione, P.; Grosso, G. Ultra-Processed Foods and Nutritional Dietary Profile: A MetaAnalysis of Nationally Representative Samples. Nutrients 2021, 13, 3390. [CrossRef]

31. Wang, L.; Martínez Steele, E.; Du, M.; Pomeranz, J.L.; O'Connor, L.E.; Herrick, K.A.; Luo, H.; Zhang, X.; Mozaffarian, D.; Zhang, F.F. Trends in Consumption of Ultraprocessed Foods Among US Youths Aged 2-19 Years, 1999-2018. JAMA 2021, 326, 519-530. [CrossRef]

32. de Araújo, C.R.B.; Ribeiro, K.D.d.S.; de Oliveira, A.F.; de Morais, I.L.; Breda, J.; Padrão, P.; Moreira, P. Degree of Processing and Nutritional Value of Children's Food Products. Public Health Nutr. 2021, 24, 5977-5984. [CrossRef]

33. Chen, X.; Zhang, Z.; Yang, H.; Qiu, P.; Wang, H.; Wang, F.; Zhao, Q.; Fang, J.; Nie, J. Consumption of Ultra-Processed Foods and Health Outcomes: A Systematic Review of Epidemiological Studies. Nutr. J. 2020, 19, 86. [CrossRef] [PubMed]

34. Elizabeth, L.; Machado, P.; Zinöcker, M.; Baker, P.; Lawrence, M. Ultra-Processed Foods and Health Outcomes: A Narrative Review. Nutrients 2020, 12, 1955. [CrossRef]

35. Lane, M.M.; Davis, J.A.; Beattie, S.; Gómez-Donoso, C.; Loughman, A.; O’Neil, A.; Jacka, F.; Berk, M.; Page, R.; Marx, W.; et al. Ultraprocessed Food and Chronic Noncommunicable Diseases: A Systematic Review and Meta-Analysis of 43 Observational Studies. Obes. Rev. 2021, 22, e13146. [CrossRef]

36. Askari, M.; Heshmati, J.; Shahinfar, H.; Tripathi, N.; Daneshzad, E. Ultra-Processed Food and the Risk of Overweight and Obesity: A Systematic Review and Meta-Analysis of Observational Studies. Int. J. Obes. 2020, 44, 2080-2091. [CrossRef] [PubMed]

37. Moradi, S.; Entezari, M.H.; Mohammadi, H.; Jayedi, A.; Lazaridi, A.-V.; Kermani, M.A.H.; Miraghajani, M. Ultra-Processed Food Consumption and Adult Obesity Risk: A Systematic Review and Dose-Response Meta-Analysis. Crit. Rev. Food Sci. Nutr. 2021. [CrossRef]

38. Jardim, M.Z.; Costa, B.V.d.L.; Pessoa, M.C.; Duarte, C.K. Ultra-Processed Foods Increase Noncommunicable Chronic Disease Risk. Nutr. Res. 2021, 95, 19-34. [CrossRef]

39. Silva Meneguelli, T.; Viana Hinkelmann, J.; Hermsdorff, H.H.M.; Zulet, M.Á.; Martínez, J.A.; Bressan, J. Food Consumption by Degree of Processing and Cardiometabolic Risk: A Systematic Review. Int. J. Food Sci. Nutr. 2020, 71, 678-692. [CrossRef]

40. Pagliai, G.; Dinu, M.; Madarena, M.P.; Bonaccio, M.; Iacoviello, L.; Sofi, F. Consumption of Ultra-Processed Foods and Health Status: A Systematic Review and Meta-Analysis. Br. J. Nutr. 2021, 125, 308-318. [CrossRef] [PubMed]

41. Monteiro, C.A.; Moubarac, J.-C.; Levy, R.B.; Canella, D.S.; Louzada, M.L.d.C.; Cannon, G. Household Availability of UltraProcessed Foods and Obesity in Nineteen European Countries. Public Health Nutr. 2018, 21, 18-26. [CrossRef]

42. Vandevijvere, S.; Jaacks, L.M.; Monteiro, C.A.; Moubarac, J.-C.; Girling-Butcher, M.; Lee, A.C.; Pan, A.; Bentham, J.; Swinburn, B. Global Trends in Ultraprocessed Food and Drink Product Sales and Their Association with Adult Body Mass Index Trajectories. Obes. Rev. 2019, 20 (Suppl. 2), 10-19. [CrossRef]

43. Poti, J.M.; Braga, B.; Qin, B. Ultra-Processed Food Intake and Obesity: What Really Matters for Health-Processing or Nutrient Content? Curr. Obes. Rep. 2017, 6, 420-431. [CrossRef]

44. Rolls, B.; Cunningham, P.; Diktas, H. Properties of Ultraprocessed Foods That Can Drive Excess Intake. Nutr. Today 2020, 55, 109-115. [CrossRef]

45. Juul, F.; Vaidean, G.; Parekh, N. Ultra-Processed Foods and Cardiovascular Diseases: Potential Mechanisms of Action. Adv. Nutr. 2021, 12, 1673-1680. [CrossRef] [PubMed] 
46. Gupta, S.; Hawk, T.; Aggarwal, A.; Drewnowski, A. Characterizing Ultra-Processed Foods by Energy Density, Nutrient Density, and Cost. Front. Nutr. 2019, 6, 70. [CrossRef] [PubMed]

47. Rauber, F.; da Costa Louzada, M.L.; Steele, E.M.; Millett, C.; Monteiro, C.A.; Levy, R.B. Ultra-Processed Food Consumption and Chronic Non-Communicable Diseases-Related Dietary Nutrient Profile in the UK (2008-2014). Nutrients 2018, 10, 587. [CrossRef] [PubMed]

48. Micek, A.; Godos, J.; Grosso, G. Nutrient and Energy Contribution of Ultra-Processed Foods in the Diet of Nations: A MetaAnalysis. Eur. J. Public Health 2021, 31, 159-160. [CrossRef]

49. Hall, K.D.; Ayuketah, A.; Brychta, R.; Cai, H.; Cassimatis, T.; Chen, K.Y.; Chung, S.T.; Costa, E.; Courville, A.; Darcey, V.; et al. Ultra-Processed Diets Cause Excess Calorie Intake and Weight Gain: An Inpatient Randomized Controlled Trial of Ad Libitum Food Intake. Cell Metab. 2019, 30, 67-77.e3. [CrossRef]

50. Fardet, A.; Rock, E. Ultra-Processed Foods: A New Holistic Paradigm? Trends Food Sci. Technol. 2019, 93, 174-184. [CrossRef]

51. Forde, C.G.; Mars, M.; de Graaf, K. Ultra-Processing or Oral Processing? A Role for Energy Density and Eating Rate in Moderating Energy Intake from Processed Foods. Curr. Dev. Nutr. 2020, 4, 1-6. [CrossRef]

52. Bolhuis, D.P.; Forde, C.G. Application of Food Texture to Moderate Oral Processing Behaviors and Energy Intake. Trends Food Sci. Technol. 2020, 106, 445-456. [CrossRef]

53. Fardet, A.; Méjean, C.; Labouré, H.; Andreeva, V.A.; Feron, G. The Degree of Processing of Foods Which Are Most Widely Consumed by the French Elderly Population Is Associated with Satiety and Glycemic Potentials and Nutrient Profiles. Food Funct. 2017, 8, 651-658. [CrossRef] [PubMed]

54. Fardet, A. Minimally Processed Foods Are More Satiating and Less Hyperglycemic than Ultra-Processed Foods: A Preliminary Study with 98 Ready-to-Eat Foods. Food Funct. 2016, 7, 2338-2346. [CrossRef]

55. Slyper, A. Oral Processing, Satiation and Obesity: Overview and Hypotheses. Diabetes Metab. Syndr. Obes. 2021, 14, 3399-3415. [CrossRef] [PubMed]

56. Mariath, A.B.; Machado, A.D.; Ferreira, L.d.N.M.; Ribeiro, S.M.L. The Possible Role of Increased Consumption of Ultra-Processed Food Products in the Development of Frailty: A Threat for Healthy Ageing? Br. J. Nutr. 2021, 1-6. [CrossRef]

57. Trakman, G.L.; Fehily, S.; Basnayake, C.; Hamilton, A.L.; Russell, E.; Wilson-O’Brien, A.; Kamm, M.A. Diet and Gut Microbiome in Gastrointestinal Disease. J. Gastroenterol. Hepatol. 2021, 1. [CrossRef]

58. Swinburn, B.A.; Sacks, G.; Hall, K.D.; McPherson, K.; Finegood, D.T.; Moodie, M.L.; Gortmaker, S.L. The Global Obesity Pandemic: Shaped by Global Drivers and Local Environments. Lancet 2011, 378, 804-814. [CrossRef]

59. Mendes, C.; Miranda, L.; Claro, R.; Horta, P. Food Marketing in Supermarket Circulars in Brazil: An Obstacle to Healthy Eating. Prev. Med. Rep. 2021, 21, 101304. [CrossRef]

60. Vandevijvere, S.; Van Dam, I. The Nature of Food Promotions over One Year in Circulars from Leading Belgian Supermarket Chains. Arch. Public Health 2021, 79, 84. [CrossRef] [PubMed]

61. Luiten, C.M.; Steenhuis, I.H.; Eyles, H.; Mhurchu, C.N.; Waterlander, W.E. Ultra-Processed Foods Have the Worst Nutrient Profile, yet They Are the Most Available Packaged Products in a Sample of New Zealand Supermarkets. Public Health Nutr. 2016, 19, 530-538. [CrossRef]

62. Hollands, G.J.; Shemilt, I.; Marteau, T.M.; Jebb, S.A.; Lewis, H.B.; Wei, Y.; Higgins, J.P.T.; Ogilvie, D. Portion, Package or Tableware Size for Changing Selection and Consumption of Food, Alcohol and Tobacco. Cochrane Database Syst. Rev. 2015, 9, CD011045. [CrossRef]

63. Juul, F.; Lin, Y.; Deierlein, A.L.; Vaidean, G.; Parekh, N. Trends in Food Consumption by Degree of Processing and Diet Quality over 17 Years: Results from the Framingham Offspring Study. Br. J. Nutr. 2021, 126, 1861-1871. [CrossRef]

64. Gibney, M.J. Ultraprocessed Foods and Their Application to Nutrition Policy. Nutr. Today 2020, 55, 16-21. [CrossRef]

65. Derbyshire, E. Are All ‘Ultra-Processed' Foods Nutritional Demons? A Commentary and Nutritional Profiling Analysis. Trends Food Sci. Technol. 2019, 94, 98-104. [CrossRef]

66. Marino, M.; Puppo, F.; Del Bo', C.; Vinelli, V.; Riso, P.; Porrini, M.; Martini, D. A Systematic Review of Worldwide Consumption of Ultra-Processed Foods: Findings and Criticisms. Nutrients 2021, 13, 2778. [CrossRef]

67. Steele, E.M.; Batis, C.; Cediel, G.; Louzada, M.L.d.C.; Khandpur, N.; Machado, P.; Moubarac, J.-C.; Rauber, F.; Jedlicki, M.R.; Levy, R.B.; et al. The Burden of Excessive Saturated Fatty Acid Intake Attributed to Ultra-Processed Food Consumption: A Study Conducted with Nationally Representative Cross-Sectional Studies from Eight Countries. J. Nutr. Sci. 2021, 10, e43. [CrossRef] [PubMed]

68. Moreira, P.V.L.; Baraldi, L.G.; Moubarac, J.-C.; Monteiro, C.A.; Newton, A.; Capewell, S.; O’Flaherty, M. Comparing Different Policy Scenarios to Reduce the Consumption of Ultra-Processed Foods in UK: Impact on Cardiovascular Disease Mortality Using a Modelling Approach. PLoS ONE 2015, 10, e0118353. [CrossRef]

69. Starck, C.S.; Blumfield, M.; Keighley, T.; Marshall, S.; Petocz, P.; Inan-Eroglu, E.; Abbott, K.; Cassettari, T.; Ali, A.; Wham, C.; et al. Nutrient Dense, Low-Cost Foods Can Improve the Affordability and Quality of the New Zealand Diet-A Substitution Modeling Study. Int. J. Environ. Res. Public Health 2021, 18, 7950. [CrossRef]

70. Verly-Jr, E.; Pereira, A.d.S.; Marques, E.S.; Horta, P.M.; Canella, D.S.; Cunha, D.B. Reducing Ultra-Processed Foods and Increasing Diet Quality in Affordable and Culturally Acceptable Diets: A Study Case from Brazil Using Linear Programming. Br. J. Nutr. 2021, 126, 572-581. [CrossRef] [PubMed]

71. Gibney, M.J. Ultra-Processed Foods: Definitions and Policy Issues. Curr. Dev. Nutr. 2019, 3, nzy077. [CrossRef] 
72. Gibney, M.J.; Forde, C.G.; Mullally, D.; Gibney, E.R. Ultra-Processed Foods in Human Health: A Critical Appraisal. Am. J. Clin. Nutr. 2017, 106, 717-724. [CrossRef]

73. Drewnowski, A.; Gupta, S.; Darmon, N. An Overlap Between “Ultraprocessed” Foods and the Preexisting Nutrient Rich Foods Index? Nutr. Today 2020, 55, 75-81. [CrossRef]

74. Romero Ferreiro, C.; Lora Pablos, D.; Gómez de la Cámara, A. Two Dimensions of Nutritional Value: Nutri-Score and NOVA. Nutrients 2021, 13, 2783. [CrossRef] [PubMed]

75. European Commission. Nutrition Claims. Available online: https:/ / ec.europa.eu/food/safety/labelling-and-nutrition/nutritionand-health-claims/nutrition-claims_en (accessed on 7 November 2021).

76. Jones, J.M. Food Processing: Criteria for Dietary Guidance and Public Health? Proc. Nutr. Soc. 2019, 78, 4-18. [CrossRef] [PubMed]

77. Estell, M.L.; Barrett, E.M.; Kissock, K.R.; Grafenauer, S.J.; Jones, J.M.; Beck, E.J. Fortification of Grain Foods and NOVA: The Potential for Altered Nutrient Intakes While Avoiding Ultra-Processed Foods. Eur. J. Nutr. 2021. [CrossRef] [PubMed]

78. Vergeer, L.; Veira, P.; Bernstein, J.T.; Weippert, M.; L'Abbé, M.R. The Calorie and Nutrient Density of More- Versus Less-Processed Packaged Food and Beverage Products in the Canadian Food Supply. Nutrients 2019, 11, 2782. [CrossRef]

79. Monteiro, C.; Cannon, G. The Food System. Ultra-Processing. Product Reformulation Will Not Improve Public Health. World Nutr. 2012, 3, 406-434.

80. Fardet, A. Complex Foods versus Functional Foods, Nutraceuticals and Dietary Supplements: Differential Health Impact (Part 1). Agro Food Ind. Hi Tech 2015, 26, 6.

81. Adams, J.; Hofman, K.; Moubarac, J.-C.; Thow, A.M. Public Health Response to Ultra-Processed Food and Drinks. BMJ 2020, 369 , m2391. [CrossRef]

82. Scrinis, G.; Monteiro, C.A. Ultra-Processed Foods and the Limits of Product Reformulation. Public Health Nutr. 2018, 21, 247-252. [CrossRef]

83. Fardet, A.; Rock, E.; Bassama, J.; Bohuon, P.; Prabhasankar, P.; Monteiro, C.; Moubarac, J.-C.; Achir, N. Current Food Classifications in Epidemiological Studies Do Not Enable Solid Nutritional Recommendations for Preventing Diet-Related Chronic Diseases: The Impact of Food Processing. Adv. Nutr. 2015, 6, 629-638. [CrossRef]

84. Zinöcker, M.K.; Lindseth, I.A. The Western Diet-Microbiome-Host Interaction and Its Role in Metabolic Disease. Nutrients 2018, 10, 365. [CrossRef] [PubMed]

85. Kwon, T.W.; Hong, J.H.; Moon, G.S.; Song, Y.S.; Kim, J.I.; Kim, J.C.; Kim, M.J. Food Technology: Challenge for Health Promotion. BioFactors 2004, 22, 279-287. [CrossRef]

86. Du, S.; Kim, H.; Rebholz, C.M. Higher Ultra-Processed Food Consumption Is Associated with Increased Risk of Incident Coronary Artery Disease in the Atherosclerosis Risk in Communities Study. J. Nutr. 2021, 151, 3746-3754. [CrossRef] [PubMed]

87. Sandoval-Insausti, H.; Blanco-Rojo, R.; Graciani, A.; López-García, E.; Moreno-Franco, B.; Laclaustra, M.; Donat-Vargas, C.; Ordovás, J.M.; Rodríguez-Artalejo, F.; Guallar-Castillón, P. Ultra-Processed Food Consumption and Incident Frailty: A Prospective Cohort Study of Older Adults. J. Gerontol. A Biol. Sci. Med. Sci. 2020, 75, 1126-1133. [CrossRef]

88. Levy, R.B.; Rauber, F.; Chang, K.; Louzada, M.L.d.C.; Monteiro, C.A.; Millett, C.; Vamos, E.P. Ultra-Processed Food Consumption and Type 2 Diabetes Incidence: A Prospective Cohort Study. Clin. Nutr. 2021, 40, 3608-3614. [CrossRef]

89. Romero Ferreiro, C.; Martín-Arriscado Arroba, C.; Cancelas Navia, P.; Lora Pablos, D.; Gómez de la Cámara, A. Ultra-Processed Food Intake and All-Cause Mortality: DRECE Cohort Study. Public Health Nutr. 2021, 1-28. [CrossRef]

90. Rauber, F.; Chang, K.; Vamos, E.P.; da Costa Louzada, M.L.; Monteiro, C.A.; Millett, C.; Levy, R.B. Ultra-Processed Food Consumption and Risk of Obesity: A Prospective Cohort Study of UK Biobank. Eur. J. Nutr. 2021, 60, 2169-2180. [CrossRef] [PubMed]

91. Blanco-Rojo, R.; Sandoval-Insausti, H.; López-Garcia, E.; Graciani, A.; Ordovás, J.M.; Banegas, J.R.; Rodríguez-Artalejo, F.; Guallar-Castillón, P. Consumption of Ultra-Processed Foods and Mortality: A National Prospective Cohort in Spain. Mayo Clin. Proc. 2019, 94, 2178-2188. [CrossRef]

92. Silva, C.F.M.; Saunders, C.; Peres, W.; Folino, B.; Kamel, T.; Dos Santos, M.S.; Padilha, P. Effect of Ultra-Processed Foods Consumption on Glycemic Control and Gestational Weight Gain in Pregnant with Pregestational Diabetes Mellitus Using Carbohydrate Counting. PeerJ 2021, 9, e10514. [CrossRef]

93. Gomes, C.d.B.; Malta, M.B.; Benício, M.H.D.; Carvalhaes, M.A.d.B.L. Consumption of Ultra-Processed Foods in the Third Gestational Trimester and Increased Weight Gain: A Brazilian Cohort Study. Public Health Nutr. 2021, 24, 3304-3312. [CrossRef]

94. Gadelha, P.C.F.P.; de Arruda, I.K.G.; Coelho, P.B.P.; Queiroz, P.M.A.; Maio, R.; da Silva Diniz, A. Consumption of Ultraprocessed Foods, Nutritional Status, and Dyslipidemia in Schoolchildren: A Cohort Study. Eur. J. Clin. Nutr. 2019, 73, 1194-1199. [CrossRef]

95. Rauber, F.; Campagnolo, P.D.B.; Hoffman, D.J.; Vitolo, M.R. Consumption of Ultra-Processed Food Products and Its Effects on Children's Lipid Profiles: A Longitudinal Study. Nutr. Metab. Cardiovasc. Dis. 2015, 25, 116-122. [CrossRef]

96. Cunha, D.B.; da Costa, T.H.M.; da Veiga, G.V.; Pereira, R.A.; Sichieri, R. Ultra-Processed Food Consumption and Adiposity Trajectories in a Brazilian Cohort of Adolescents: ELANA Study. Nutr. Diabetes 2018, 8, 28. [CrossRef]

97. Bawaked, R.A.; Fernández-Barrés, S.; Navarrete-Muñoz, E.M.; González-Palacios, S.; Guxens, M.; Irizar, A.; Lertxundi, A.; Sunyer, J.; Vioque, J.; Schröder, H.; et al. Impact of Lifestyle Behaviors in Early Childhood on Obesity and Cardiometabolic Risk in Children: Results from the Spanish INMA Birth Cohort Study. Pediatr. Obes. 2020, 15, e12590. [CrossRef] 
98. Costa, C.S.; Rauber, F.; Leffa, P.S.; Sangalli, C.N.; Campagnolo, P.D.B.; Vitolo, M.R. Ultra-Processed Food Consumption and Its Effects on Anthropometric and Glucose Profile: A Longitudinal Study during Childhood. Nutr. Metab. Cardiovasc. Dis. 2019, 29, 177-184. [CrossRef] [PubMed]

99. Vedovato, G.M.; Vilela, S.; Severo, M.; Rodrigues, S.; Lopes, C.; Oliveira, A. Ultra-Processed Food Consumption, Appetitive Traits and BMI in Children: A Prospective Study. Br. J. Nutr. 2021, 125, 1427-1436. [CrossRef] [PubMed]

100. de Melo, J.M.M.; Dourado, B.L.L.F.S.; de Menezes, R.C.E.; Longo-Silva, G.; da Silveira, J.A.C. Early Onset of Overweight among Children from Low-Income Families: The Role of Exclusive Breastfeeding and Maternal Intake of Ultra-Processed Food. Pediatr. Obes. 2021, 16, e12825. [CrossRef]

101. Machado Azeredo, C.; Cortese, M.; Costa, C.d.S.; Bjornevik, K.; Barros, A.J.D.; Barros, F.C.; Santos, I.S.; Matijasevich, A. UltraProcessed Food Consumption during Childhood and Asthma in Adolescence: Data from the 2004 Pelotas Birth Cohort Study. Pediatr. Allergy Immunol. 2020, 31, 27-37. [CrossRef] [PubMed]

102. Schnabel, L.; Kesse-Guyot, E.; Allès, B.; Touvier, M.; Srour, B.; Hercberg, S.; Buscail, C.; Julia, C. Association Between Ultraprocessed Food Consumption and Risk of Mortality Among Middle-Aged Adults in France. JAMA Intern. Med. 2019, 179, 490-498. [CrossRef]

103. Rico-Campà, A.; Martínez-González, M.A.; Alvarez-Alvarez, I.; Mendonça, R.d.D.; de la Fuente-Arrillaga, C.; Gómez-Donoso, C.; Bes-Rastrollo, M. Association between Consumption of Ultra-Processed Foods and All Cause Mortality: SUN Prospective Cohort Study. BMJ 2019, 365, 11949. [CrossRef]

104. Kim, H.; Hu, E.A.; Rebholz, C.M. Ultra-Processed Food Intake and Mortality in the United States: Results from the Third National Health and Nutrition Examination Survey (NHANES III 1988-1994). Public Health Nutr. 2019, 22, 1777-1785. [CrossRef]

105. Bonaccio, M.; Di Castelnuovo, A.; Costanzo, S.; De Curtis, A.; Persichillo, M.; Sofi, F.; Cerletti, C.; Donati, M.B.; de Gaetano, G.; Iacoviello, L.; et al. Ultra-Processed Food Consumption Is Associated with Increased Risk of All-Cause and Cardiovascular Mortality in the Moli-Sani Study. Am. J. Clin. Nutr. 2021, 113, 446-455. [CrossRef]

106. Beslay, M.; Srour, B.; Méjean, C.; Allès, B.; Fiolet, T.; Debras, C.; Chazelas, E.; Deschasaux, M.; Wendeu-Foyet, M.G.; Hercberg, S.; et al. Ultra-Processed Food Intake in Association with BMI Change and Risk of Overweight and Obesity: A Prospective Analysis of the French NutriNet-Santé Cohort. PLoS Med. 2020, 17, e1003256. [CrossRef] [PubMed]

107. Mendonça, R.d.D.; Pimenta, A.M.; Gea, A.; de la Fuente-Arrillaga, C.; Martinez-Gonzalez, M.A.; Lopes, A.C.S.; Bes-Rastrollo, M. Ultraprocessed Food Consumption and Risk of Overweight and Obesity: The University of Navarra Follow-Up (SUN) Cohort Study. Am. J. Clin. Nutr. 2016, 104, 1433-1440. [CrossRef] [PubMed]

108. Li, M.; Shi, Z. Ultra-Processed Food Consumption Associated with Overweight/Obesity among Chinese Adults-Results from China Health and Nutrition Survey 1997-2011. Nutrients 2021, 13, 2796. [CrossRef]

109. Konieczna, J.; Morey, M.; Abete, I.; Bes-Rastrollo, M.; Ruiz-Canela, M.; Vioque, J.; Gonzalez-Palacios, S.; Daimiel, L.; Salas-Salvadó, J.; Fiol, M.; et al. Contribution of Ultra-Processed Foods in Visceral Fat Deposition and Other Adiposity Indicators: Prospective Analysis Nested in the PREDIMED-Plus Trial. Clin. Nutr. 2021, 40, 4290-4300. [CrossRef]

110. Sandoval-Insausti, H.; Jiménez-Onsurbe, M.; Donat-Vargas, C.; Rey-García, J.; Banegas, J.R.; Rodríguez-Artalejo, F.; Guallar-Castillón, P. Ultra-Processed Food Consumption Is Associated with Abdominal Obesity: A Prospective Cohort Study in Older Adults. Nutrients 2020, 12, 2368. [CrossRef]

111. Cordova, R.; Kliemann, N.; Huybrechts, I.; Rauber, F.; Vamos, E.P.; Levy, R.B.; Wagner, K.-H.; Viallon, V.; Casagrande, C.; Nicolas, G.; et al. Consumption of Ultra-Processed Foods Associated with Weight Gain and Obesity in Adults: A Multi-National Cohort Study. Clin. Nutr. 2021, 40, 5079-5088. [CrossRef] [PubMed]

112. Canhada, S.L.; Luft, V.C.; Giatti, L.; Duncan, B.B.; Chor, D.; da Fonseca, M.d.J.M.; Matos, S.M.A.; Molina, M.d.C.B.; Barreto, S.M.; Levy, R.B.; et al. Ultra-Processed Foods, Incident Overweight and Obesity, and Longitudinal Changes in Weight and Waist Circumference: The Brazilian Longitudinal Study of Adult Health (ELSA-Brasil). Public Health Nutr. 2020, 23, $1076-1086$. [CrossRef]

113. Rohatgi, K.W.; Tinius, R.A.; Cade, W.T.; Steele, E.M.; Cahill, A.G.; Parra, D.C. Relationships between Consumption of UltraProcessed Foods, Gestational Weight Gain and Neonatal Outcomes in a Sample of US Pregnant Women. PeerJ 2017, 5, e4091. [CrossRef]

114. Leone, A.; Martínez-González, M.Á.; Craig, W.; Fresán, U.; Gómez-Donoso, C.; Bes-Rastrollo, M. Pre-Gestational Consumption of Ultra-Processed Foods and Risk of Gestational Diabetes in a Mediterranean Cohort. The SUN Project. Nutrients 2021, 13, 2202. [CrossRef] [PubMed]

115. Chang, K.; Khandpur, N.; Neri, D.; Touvier, M.; Huybrechts, I.; Millett, C.; Vamos, E.P. Association Between Childhood Consumption of Ultraprocessed Food and Adiposity Trajectories in the Avon Longitudinal Study of Parents and Children Birth Cohort. JAMA Pediatr. 2021, 175, e211573. [CrossRef]

116. Costa, C.d.S.; Assunção, M.C.F.; Loret de Mola, C.; Cardoso, J.d.S.; Matijasevich, A.; Barros, A.J.D.; Santos, I.S. Role of UltraProcessed Food in Fat Mass Index between 6 and 11 Years of Age: A Cohort Study. Int. J. Epidemiol. 2021, 50, 256-265. [CrossRef] [PubMed]

117. Srour, B.; Fezeu, L.K.; Kesse-Guyot, E.; Allès, B.; Méjean, C.; Andrianasolo, R.M.; Chazelas, E.; Deschasaux, M.; Hercberg, S.; Galan, P.; et al. Ultra-Processed Food Intake and Risk of Cardiovascular Disease: Prospective Cohort Study (NutriNet-Santé). BMJ 2019, 365, 11451. [CrossRef] 
118. Juul, F.; Vaidean, G.; Lin, Y.; Deierlein, A.L.; Parekh, N. Ultra-Processed Foods and Incident Cardiovascular Disease in the Framingham Offspring Study. J. Am. Coll. Cardiol. 2021, 77, 1520-1531. [CrossRef] [PubMed]

119. Zhong, G.-C.; Gu, H.-T.; Peng, Y.; Wang, K.; Wu, Y.-Q.-L.; Hu, T.-Y.; Jing, F.-C.; Hao, F.-B. Association of Ultra-Processed Food Consumption with Cardiovascular Mortality in the US Population: Long-Term Results from a Large Prospective Multicenter Study. Int. J. Behav. Nutr. Phys. Act. 2021, 18, 21. [CrossRef]

120. da Silva Scaranni, P.D.O.; de Oliveira Cardoso, L.; Chor, D.; Melo, E.C.P.; Matos, S.M.A.; Giatti, L.; Barreto, S.M.; da Fonseca, M.D.J.M. Ultra-Processed Foods, Changes in Blood Pressure and Incidence of Hypertension: The Brazilian Longitudinal Study of Adult Health (ELSA-Brasil). Public Health Nutr. 2021, 24, 3352-3360. [CrossRef]

121. Monge, A.; Silva Canella, D.; López-Olmedo, N.; Lajous, M.; Cortés-Valencia, A.; Stern, D. Ultraprocessed Beverages and Processed Meats Increase the Incidence of Hypertension in Mexican Women. Br. J. Nutr. 2021, 126, 600-611. [CrossRef]

122. de Mendonça, R.D.; Lopes, A.C.S.; Pimenta, A.M.; Gea, A.; Martinez-Gonzalez, M.A.; Bes-Rastrollo, M. Ultra-Processed Food Consumption and the Incidence of Hypertension in a Mediterranean Cohort: The Seguimiento Universidad de Navarra Project. Am. J. Hypertens. 2017, 30, 358-366. [CrossRef]

123. Llavero-Valero, M.; Martín, J.E.-S.; Martínez-González, M.A.; Basterra-Gortari, F.J.; de la Fuente-Arrillaga, C.; Bes-Rastrollo, M. Ultra-Processed Foods and Type-2 Diabetes Risk in the SUN Project: A Prospective Cohort Study. Clin. Nutr. 2021, 40, $2817-2824$. [CrossRef]

124. Srour, B.; Fezeu, L.K.; Kesse-Guyot, E.; Allès, B.; Debras, C.; Druesne-Pecollo, N.; Chazelas, E.; Deschasaux, M.; Hercberg, S.; Galan, P.; et al. Ultraprocessed Food Consumption and Risk of Type 2 Diabetes Among Participants of the NutriNet-Santé Prospective Cohort. JAMA Intern. Med. 2020, 180, 283-291. [CrossRef] [PubMed]

125. Zhang, S.; Gan, S.; Zhang, Q.; Liu, L.; Meng, G.; Yao, Z.; Wu, H.; Gu, Y.; Wang, Y.; Zhang, T.; et al. Ultra-Processed Food Consumption and the Risk of Non-Alcoholic Fatty Liver Disease in the Tianjin Chronic Low-Grade Systemic Inflammation and Health Cohort Study. Int. J. Epidemiol. 2021, dyab174. [CrossRef] [PubMed]

126. Fiolet, T.; Srour, B.; Sellem, L.; Kesse-Guyot, E.; Allès, B.; Méjean, C.; Deschasaux, M.; Fassier, P.; Latino-Martel, P.; Beslay, M.; et al. Consumption of Ultra-Processed Foods and Cancer Risk: Results from NutriNet-Santé Prospective Cohort. BMJ 2018, 360, k322. [CrossRef]

127. Vasseur, P.; Dugelay, E.; Benamouzig, R.; Savoye, G.; Lan, A.; Srour, B.; Hercberg, S.; Touvier, M.; Hugot, J.-P.; Julia, C.; et al. Dietary Patterns, Ultra-Processed Food, and the Risk of Inflammatory Bowel Diseases in the NutriNet-Santé Cohort. Inflamm. Bowel Dis. 2021, 27, 65-73. [CrossRef]

128. Narula, N.; Wong, E.C.L.; Dehghan, M.; Mente, A.; Rangarajan, S.; Lanas, F.; Lopez-Jaramillo, P.; Rohatgi, P.; Lakshmi, P.V.M.; Varma, R.P.; et al. Association of Ultra-Processed Food Intake with Risk of Inflammatory Bowel Disease: Prospective Cohort Study. BMJ 2021, 374, n1554. [CrossRef]

129. Schnabel, L.; Buscail, C.; Sabate, J.-M.; Bouchoucha, M.; Kesse-Guyot, E.; Allès, B.; Touvier, M.; Monteiro, C.A.; Hercberg, S.; Benamouzig, R.; et al. Association Between Ultra-Processed Food Consumption and Functional Gastrointestinal Disorders: Results from the French NutriNet-Santé Cohort. Am. J. Gastroenterol. 2018, 113, 1217-1228. [CrossRef] [PubMed]

130. Lo, C.-H.; Khandpur, N.; Rossato, S.; Lochhead, P.; Lopes, E.; Burke, K.; Richter, J.; Song, M.; Korat, A.; Sun, Q.; et al. UltraProcessed Foods and Risk of Crohn's Disease and Ulcerative Colitis: A Prospective Cohort Study. Clin. Gastroenterol. Hepatol. 2021. [CrossRef]

131. Adjibade, M.; Julia, C.; Allès, B.; Touvier, M.; Lemogne, C.; Srour, B.; Hercberg, S.; Galan, P.; Assmann, K.E.; Kesse-Guyot, E. Prospective Association between Ultra-Processed Food Consumption and Incident Depressive Symptoms in the French NutriNetSanté Cohort. BMC Med. 2019, 17, 78. [CrossRef]

132. Gómez-Donoso, C.; Sánchez-Villegas, A.; Martínez-González, M.A.; Gea, A.; de Mendonça, R.D.; Lahortiga-Ramos, F.; Bes-Rastrollo, M. Ultra-Processed Food Consumption and the Incidence of Depression in a Mediterranean Cohort: The SUN Project. Eur. J. Nutr. 2020, 59, 1093-1103. [CrossRef]

133. Rey-García, J.; Donat-Vargas, C.; Sandoval-Insausti, H.; Bayan-Bravo, A.; Moreno-Franco, B.; Banegas, J.R.; Rodríguez-Artalejo, F.; Guallar-Castillón, P. Ultra-Processed Food Consumption Is Associated with Renal Function Decline in Older Adults: A Prospective Cohort Study. Nutrients 2021, 13, 428. [CrossRef]

134. Zhang, T.; Gan, S.; Ye, M.; Meng, G.; Zhang, Q.; Liu, L.; Wu, H.; Gu, Y.; Zhang, S.; Wang, Y.; et al. Association between Consumption of Ultra-Processed Foods and Hyperuricemia: TCLSIH Prospective Cohort Study. Nutr. Metab. Cardiovasc. Dis. 2021, 31, 1993-2003. [CrossRef] [PubMed]

135. Leffa, P.S.; Hoffman, D.J.; Rauber, F.; Sangalli, C.N.; Valmórbida, J.L.; Vitolo, M.R. Longitudinal Associations between UltraProcessed Foods and Blood Lipids in Childhood. Br. J. Nutr. 2020, 124, 341-348. [CrossRef]

136. Donat-Vargas, C.; Sandoval-Insausti, H.; Rey-García, J.; Moreno-Franco, B.; Åkesson, A.; Banegas, J.R.; Rodríguez-Artalejo, F.; Guallar-Castillón, P. High Consumption of Ultra-Processed Food Is Associated with Incident Dyslipidemia: A Prospective Study of Older Adults. J. Nutr. 2021, 151, 2390-2398. [CrossRef]

137. Borge, T.C.; Biele, G.; Papadopoulou, E.; Andersen, L.F.; Jacka, F.; Eggesbø, M.; Caspersen, I.H.; Aase, H.; Meltzer, H.M.; Brantsæter, A.L. The Associations between Maternal and Child Diet Quality and Child ADHD—Findings from a Large Norwegian Pregnancy Cohort Study. BMC Psychiatry 2021, 21, 139. [CrossRef] 
138. Zhang, S.; Gu, Y.; Rayamajhi, S.; Thapa, A.; Meng, G.; Zhang, Q.; Liu, L.; Wu, H.; Zhang, T.; Wang, X.; et al. Ultra-Processed Food Intake Is Associated with Grip Strength Decline in Middle-Aged and Older Adults: A Prospective Analysis of the TCLSIH Study. Eur. J. Nutr. 2021. [CrossRef] [PubMed]

139. Huybrechts, I.; Vereecken, C.; De Bacquer, D.; Vandevijvere, S.; Van Oyen, H.; Maes, L.; Vanhauwaert, E.; Temme, L.; De Backer, G.; De Henauw, S. Reproducibility and Validity of a Diet Quality Index for Children Assessed Using a FFQ. Br. J. Nutr. 2010, 104, 135-144. [CrossRef]

140. Kouvari, M.; Chrysohoou, C.; Georgousopoulou, E.; Skoumas, J.; Pitsavos, C.; Panagiotakos, D.B. Ultra-Processed Foods and Ten-Year Cardiovascular Disease Incidence in a Mediterranean Population: Results from a Population-Based Cohort Study. Eur. Heart J. 2021, 42, 2433. [CrossRef]

141. Bonaccio, M.; Di Castelnuovo, A.; Ruggiero, E.; Costanzo, S.; Esposito, S.; Persichillo, M.; Cerletti, C.; Donati, M.; de Gaetano, G.; Iacoviello, L. Ultra-Processed Food Consumption Modifies the Association of Nutri-Score with All-Cause Mortality. Eur. J. Public Health 2021, 31, 169-170. [CrossRef]

142. Kipnis, V.; Subar, A.F.; Midthune, D.; Freedman, L.S.; Ballard-Barbash, R.; Troiano, R.P.; Bingham, S.; Schoeller, D.A.; Schatzkin, A.; Carroll, R.J. Structure of Dietary Measurement Error: Results of the OPEN Biomarker Study. Am. J. Epidemiol. 2003, 158, 14-21. [CrossRef] [PubMed]

143. Subar, A.F.; Freedman, L.S.; Tooze, J.A.; Kirkpatrick, S.I.; Boushey, C.; Neuhouser, M.L.; Thompson, F.E.; Potischman, N.; Guenther, P.M.; Tarasuk, V.; et al. Addressing Current Criticism Regarding the Value of Self-Report Dietary Data. J. Nutr. 2015, 145, 2639-2645. [CrossRef] [PubMed]

144. Willett, W. Monographs in Epidemiology and Biostatistics. Nutritional Epidemiology, 3rd ed.; Oxford University Press: New York, NY, USA, 2012; ISBN 978-0-19-975403-8.

145. Hu, F.B.; Stampfer, M.J.; Rimm, E.; Ascherio, A.; Rosner, B.A.; Spiegelman, D.; Willett, W.C. Dietary Fat and Coronary Heart Disease: A Comparison of Approaches for Adjusting for Total Energy Intake and Modeling Repeated Dietary Measurements. Am. J. Epidemiol. 1999, 149, 531-540. [CrossRef] [PubMed]

146. Willett, W.C.; Howe, G.R.; Kushi, L.H. Adjustment for Total Energy Intake in Epidemiologic Studies. Am. J. Clin. Nutr. 1997, 65, 1220S-1228S. [CrossRef]

147. Padilha, P.; Felizardo, C.; Saunders, C.; Cunha, L.; Pinheiro, A.; Belfort, G.; Santos, K.; Ferreira, N. Consumption of Ultraprocessed Foods by Pregnant Women with Diabetes Mellitus (P11-021-19). Curr. Dev. Nutr. 2019, 3, nzz048-P11. [CrossRef]

148. Rezende-Alves, K.; Hermsdorff, H.; Miranda, A.; Lopes, A.; Bressan, J.; Pimenta, A. Food processing and risk of hypertension: Cohort of Universities of Minas Gerais, Brazil (CUME Project). Public Health Nutr. 2021, 24, 4071-4079. [CrossRef]

149. Lange, T.; Vansteelandt, S.; Bekaert, M. A Simple Unified Approach for Estimating Natural Direct and Indirect Effects. Am. J. Epidemiol. 2012, 176, 190-195. [CrossRef]

150. Lockwood, C.M.; DeFrancesco, C.A.; Elliot, D.L.; Beresford, S.A.A.; Toobert, D.J. Mediation Analyses: Applications in Nutrition Research and Reading the Literature. J. Am. Diet. Assoc. 2010, 110, 753-762. [CrossRef]

151. Widmer, R.J.; Flammer, A.J.; Lerman, L.O.; Lerman, A. The Mediterranean Diet, Its Components, and Cardiovascular Disease. Am. J. Med. 2015, 128, 229-238. [CrossRef]

152. Crimarco, A.; Landry, M.J.; Gardner, C.D. Ultra-Processed Foods, Weight Gain, and Co-Morbidity Risk. Curr. Obes. Rep. 2021, 1-13. [CrossRef] [PubMed]

153. Bandy, L.K.; Scarborough, P.; Harrington, R.A.; Rayner, M.; Jebb, S.A. Reductions in Sugar Sales from Soft Drinks in the UK from 2015 to 2018. BMC Med. 2020, 18, 20. [CrossRef] [PubMed]

154. Jacobs, D.R.; Tapsell, L.C. Food, Not Nutrients, Is the Fundamental Unit in Nutrition. Nutr. Rev. 2007, 65, 439-450. [CrossRef]

155. Barabási, A.-L.; Menichetti, G.; Loscalzo, J. The Unmapped Chemical Complexity of Our Diet. Nat. Food 2020, 1, 33-37. [CrossRef]

156. Cancer Research UK. What Is a Healthy Diet? Available online: https://www.cancerresearchuk.org/about-cancer/causes-ofcancer / diet-and-cancer/what-is-a-healthy-diet (accessed on 11 October 2021).

157. NHS. The Eatwell Guide. Available online: https:/ / www.nhs.uk/live-well/eat-well/the-eatwell-guide/ (accessed on 11 October 2021).

158. GOV.UK. Government Recommendations for Energy and Nutrients for Males and Females Aged 1-18 Years and 19+ Years. Available online: https://assets.publishing.service.gov.uk/government/uploads/system/uploads/attachment_data/file/61 8167/government_dietary_recommendations.pdf (accessed on 14 October 2021).

159. UNICEF. Prevention of Overweight and Obesity in Children and Adolescents. Available online: https://www.unicef.org/media/ 92336/file/Programming-Guidance-Overweight-Prevention.pdf (accessed on 3 November 2021).

160. World Health Organisation. Report of the Commission on Ending Childhood Obesity. Available online: http:/ /apps.who.int/ iris/bitstream/handle/10665/204176/9789241510066_eng.pdf (accessed on 3 November 2021).

161. Pan American Health Organisation. Nutrient Profile Model. Available online: https://iris.paho.org/bitstream/handle/10665.2/ 18621/9789275118733_eng.pdf (accessed on 19 October 2021). 
162. Ministry of Health of Brazil. Dietary Guidelines for the Brazilian Population. Available online: https://bvsms.saude.gov.br/bvs/ publicacoes/dietary_guidelines_brazilian_population.pdf (accessed on 14 October 2021).

163. Food and Agriculture Organization of the United Nations. Dietary Guidelines for the Uruguayan Population: For a Healthy, Shared and Enjoyable Diet. Available online: http://www.fao.org/nutrition/education/food-dietary-guidelines/regions/ uruguay/en/ (accessed on 14 October 2021).

164. The Israeli Ministry of Health. Nutritional Recommendations. Available online: https://www.health.gov.il/PublicationsFiles/ dietary\%20guidelines\%20EN.pdf (accessed on 18 October 2021).

165. High Council of Public Health. Relatif Aux Objectifs de Santé Publique Quantifiés Pour La Politique Nutritionnelle de Santé Publique (PNNS) 2018-2022 [Quantified Public Health Objectives for Public Health Nutrition Policy (PNNS) 2018-2022]. Available online: https: / / www.hcsp.fr/explore.cgi/avisrapportsdomaine?clefr=648 (accessed on 13 November 2021). 